\title{
60 AÑOS DE LA APROBACIÓN DEL TÍTULO DE FISIOTERAPIA Y DE LA PRIMERA ESCUELA DE FISIOTERAPIA RECONOCIDA, LA DE SALUS INFIRMORUM EN EL CENTRO INFANTIL “CASA DEL NIÑO” DE MADRID
}

\author{
Elena Chamorro Rebollo \\ Facultad de Enfermería y Fisioterapia Salus Infirmorum de la Universidad Pontificia de Salamanca \\ elena_chamorro@salusinfirmorum.es \\ ORCID iD: https://orcid.org/0000-0001-8515-5471 \\ José Siles González \\ Departamento de Enfermería / Facultad Ciencias de la Salud. Universidad de Alicante \\ jose.siles@ua.es \\ ORCID iD: https://orcid.org/0000-0003-3046-639X \\ Cristina Díaz Pérez \\ Facultad de Enfermería y Fisioterapia Salus Infirmorum de la Universidad Pontificia de Salamanca \\ cristina_diaz@salusinfirmorum.es \\ ORCID iD::https://orcid.org/0000-0002-9953-7304 \\ Óscar Álvarez López \\ Facultad de Enfermería y Fisioterapia Salus Infirmorum de la Universidad Pontificia de Salamanca \\ oscar_alvarez@salusinfirmorum.es \\ ORCID iD: https://orcid.org/0000-0002-6562-8005
}

Recibido: 1 diciembre 2017; Aprobado: 6 julio 2018.

Cómo citar este artículo/Citation: Chamorro Rebollo, Elena; Siles González, José; Díaz Pérez, Cristina y Álvarez López, Óscar (2018), “60 años de la aprobación del título de Fisioterapia y de la primera escuela de Fisioterapia reconocida, la de Salus Infirmorum en el centro infantil “Casa del Niño" de Madrid”, Asclepio, 70 (2): p233. https://doi.org/10.3989/asclepio.2018.17

RESUMEN: Se acaban de cumplir 60 años de la aprobación de la especialidad de Fisioterapia para los Ayudantes Técnicos Sanitarios, así como la creación de las primeras escuelas de Fisioterapia. El presente artículo justificará cómo el conjunto de brotes epidémicos de poliomielitis en España, influyeron de forma decisiva en el nacimiento de profesiones sanitarias como la Fisioterapia. Por otro lado, se reconstruirá el proceso de institucionalización, nacimiento y desarrollo en sus primeros años de la Escuela de Fisioterapia Salus Infirmorum, la primera en ser aprobada por el Ministerio de Educación. Salus Infirmorum, con la creación del centro infantil "Casa del Niño" consiguió aunar la formación de fisioterapeutas y el tratamiento de niños con problemas motóricos como consecuencia de la poliomielitis. En el centro se atendió a más de 680 niños y se formaron en ella 373 enfermeras fisioterapeutas, siendo reconocido como Obra de interés social, por la Comisaría de Asistencia Social del Ministerio de Educación Nacional, en orden 6 de junio de 1958.

PALABRAS CLAVE: Poliomielitis; Fisioterapia; Enfermería; Educación; Historia.

60 YEARS SINCE APPROVAL OF THE PHYSIOTHERAPY DEGREE AND THE FIRST RECOGNIZED PHYSIOTHERAPY SCHOOL, SALUS INFIRMORUM UBICATED IN THE CHILDREN'S CENTER “CASA DEL NIÑO” IN MADRID

ABSTRACT: Sixty years have passed since approval of the Physiotherapy specialty for licensed practical nurses, as well as the establishment of the first Physiotherapy Schools. This paper will explain how the set of epidemic outbreaks of poliomyelitis in Spain, had a decisive influence on the birth of health professions such as Physiotherapy. On the other hand, throughout it, the process of institutionalization of Salus Infirmorum, the first Physiotherapy College recognized by the Ministry of Education, its birth and its first year's early development will be reconstructed. Salus Infirmorum, with the creation of the children's center "Casa del Niño" managed to combine the physiotherapists training with the treatment of children with motor disorders as a result of poliomyelitis. In the healthcare center, more than 680 children were attended and 373 physiotherapist-nurses were trained, being recognized as a Social Interest Group, by the Social Assistance Commission of the Ministry of National Education, in order June 6, 1958

KEY WORDS: Poliomyelitis; Physical TherapySpecialty; Nursing; Education; History.

Copyright: @ 2018 CSIC. Este es un artículo de acceso abierto distribuido bajo los términos de la licencia de uso y distribución Creative Commons Reconocimiento 4.0 Internacional (CC BY 4.0). 


\section{INTRODUCCIÓN}

En 2017 se cumplieron sesenta años de la aprobación de la especialidad de Fisioterapia para los Ayudantes Técnicos Sanitarios (ATS) ${ }^{1}$. Posteriormente, la Orden Ministerial del 7 de Octubre de $1957^{2}$ aprobó el programa de estudios para la enseñanza de la especialidad. A partir de esta legislación surgieron las escuelas profesionales, siendo la Escuela de ATS de la Hermandad Salus Infirmorum de Madrid, la primera en ser reconocida por el Ministerio de Educación ${ }^{3}$.

El origen y desarrollo de la Fisioterapia como especialidad de los ATS, al igual que otras profesiones sanitarias, como la Terapia Ocupacional, y especialidades médicas como Medicina del Trabajo, Traumatología y Cirugía Ortopédica o Rehabilitación, guardan relación con el desarrollo de sucesos relevantes acontecidos a lo largo del siglo XX. Toledo Maruhenda (2010) y González Dominguez (2006) identifican algunos aspectos clave para el proceso de institucionalización de la Fisioterapia en España: la aprobación de la Ley de Accidentes del Trabajo de 1900, como medida de protección social; los accidentes laborales y de tráfico, como consecuencia de una mayor actividad económica e industrial del país; o la demanda social generada por la discapacidad derivada de enfermedades infantiles como la poliomielitis, la parálisis infantil y la parálisis braquial obstétrica, entre otras.

Especialmente relacionado con este último aspecto, el de las discapacidades de los niños, un enfoque de estudio especialmente interesante, llevado a cabo por algunos autores como Ballester y Porras (2012) y Ballester, Porras y Baguena (2015), y relacionado con el surgimiento y consolidación de nuevas figuras profesionales, es el conjunto de visitas a España de expertos de la Organización Mundial de la Salud (OMS) con el fin de prestar asesoramiento en la puesta en marcha de un plan de Rehabilitación integral, conocido posteriormente como Plan de Operaciones ESPAÑA-23, dirigido a la rehabilitación de los niños con discapacidades físicas. (Ballester, Porras y Báguena, 2015).

Los resultados derivados de las visitas realizadas por consultores internacionales quedaron recogidas en una serie de informes, realizados entre los años 1956 y 1973 a la finalización de cada una de las estancias realizadas. Uno de los objetivos clave de esta interacción era evaluar la infraestructura de los servicios de Rehabilitación y la formación del personal que los integraba, con el fin de marcar unas pautas a corto y medio plazo que trataran de planificar la formación y competencias de los profesionales vinculados al tratamiento de la discapacidad. De hecho, el informe derivado de la primera visita, realizada por Safford y Jansson en el año $1956^{4}$, puso de manifiesto la inexistencia de profesionales formados en técnicas propias de Fisioterapia y la necesidad de legislar el ejercicio de esta profesión para disponer de especialistas formados en la aplicación de medios físicos. Ante este hecho, una de las primeras recomendaciones fue la de crear en Madrid una escuela de Fisioterapia con la que formar a profesionales que pudieran dar respuesta a la demanda social generada por la gran cantidad de inválidos derivados de las epidemias de poliomielitis.

El objetivo de este trabajo es doble. Por un lado, constatar cómo el conjunto de brotes epidémicos de poliomielitis en España, vividos especialmente a partir de 1950, influyeron de forma decisiva en el nacimiento de profesiones sanitarias como la Fisioterapia y la Terapia Ocupacional, además de ofrecer un claro impulso favorecedor al nacimiento oficial de la especialidad médica de Rehabilitación, aprobada oficialmente en $1969^{5}$. Por otro lado, dentro del periodo anterior, caracterizado por el surgimiento de nuevos profesionales, reconstruir el proceso de institucionalización, nacimiento y desarrollo en sus primeros años, de la Escuela de Fisioterapia Salus Infirmorum. Esta institución, de carácter privado y con actividad formativa y asistencial, fue la primera en ser aprobada por el Ministerio de Educación ${ }^{6}$.

En el curso académico 1957-58, tanto en la Escuela de Salus Infirmorum como en las Facultades de Medicina de las universidades de Madrid y de Valencia, se inició la actividad docente de una nueva especialidad, la de Fisioterapia, que con el paso de los años daría lugar a una nueva figura profesional, la del fisioterapeuta.

\section{EL ORIGEN DE LA FISIOTERAPIA Y DE OTRAS PROFESIONES SANITARIAS}

La discapacidad física fue una realidad social desde el inicio siglo XX como consecuencia del número de discapacitados físicos provocado por factores como los distintos conflictos bélicos, las lesiones laborales - las secuelas producidas por enfermedades como la poliomielitis o la tuberculosis. Este hecho puso de manifiesto la necesidad de desarrollar iniciativas organizativas novedosas, que permitieran hacer frente a las necesidades actuales. Algunas de estas iniciativas contemplaban acciones relacionadas con un mejor uso de los espacios y recursos disponibles, nuevas formas de tratamiento y de recuperación y, en consecuencia, la necesidad de personal especializado para llevar a cabo estas acciones. 
El desarrollo industrial de finales del siglo XIX, y ante las demandas por parte de los trabajadores para mejorar sus condiciones laborales, se planteó la necesidad de regular el procedimiento para atender a las víctimas de accidentes en su actividad laboral, aprobándose el 31 de enero de 1900 la Ley de Accidentes de Trabajo7 (Martínez, 2009, p.122). La ley otorgaba el derecho a una indemnización, así como a la asistencia médica y farmacéutica al trabajador cuya lesión provocara en él una incapacidad, temporal o definitiva. Serían los médicos los encargados de prestar esa atención sanitaria y de gestionar los accidentes laborales, aunque no fue hasta la reforma de la Ley de Accidentes del Trabajo de 1922 cuando surgió una especialidad médica para ello, la de Medicina del Trabajo ${ }^{8}$ (Porras, Báguena y Toledo, 2017). El artículo 23 de dicha ley contemplaba la creación de un servicio especial de reeducación, que tenía por objeto "devolver a éstos la capacidad profesional suficiente para que puedan atender por sí mismos a su subsistencia"g. En cumplimiento de este requisito legal, se creó en Madrid el Instituto de Reeducación Profesional de Inválidos del Trabajo (IRPIT) en 1924. Entre las funciones del IRPIT se encontraba la readaptación funcional de los accidentados, su reeducación profesional y la tutela social de los reeducados. (Martínez, 2009, p. 127).

Previamente, a instancias del médico militar Manuel Bastos Ansart (1887-1973), y como consecuencia del número de heridos en la intensificación de la Guerra de Marruecos, en 1921, se solicitó la creación de un "Instituto de Rehabilitación de mutilados e inutilizados de la campaña", creándose a tal efecto la Clínica Ortopédica y Reeducación en el hospital Militar del barrio madrileño de Carabanchel (Bastos, 1921). En 1933, el IRPIT se transformó en el Instituto de Reeducación de Inválidos (INRI), como consecuencia de la reforma de la Ley de Accidentes del Trabajo de 1932, consiguiendo así un centro especializado para la reeducación de inválidos "de todo orden"10, incluidos aquellos derivados de enfermedades infecciosas como la poliomielitis, que dejó graves secuelas en la infancia española tras la epidemia de 1928. Los médicos especialistas en Ortopedia y Traumatología pasaron a tomar un protagonismo relevante en el tratamiento de los discapacitados, constituyéndose la Sociedad Española de Cirugía Ortopédica y Traumatología en 1935 (Martínez, 2009, p.131).

El estallido de la Guerra Civil (1936-1939) truncó el desarrollo alcanzado en la red sanitaria-asistencial para la reeducación de inválidos, hasta tal punto que costó toda una década recuperar la situación anterior al conflicto bélico.
El inicio de los brotes epidémicos de poliomielitis en España y el elevado número de afectados que la enfermedad provocaba favorecieron que las autoridades políticas y sanitarias adoptaran medidas estatales de carácter urgente para luchar contra la invalidez. Estas medidas se materializaron, por un lado, con la creación de los llamados Centros de Lucha contra la Polio en 1947 y en 1949, que aparecen los centros especializados de reeducación y divulgación de la Rehabilitación, surgiendo así el Patronato Nacional de Lucha contra la invalidez ${ }^{11}$.

Finalmente, una nueva medida adoptada dentro del incipiente plan integral de asistencia al discapacitado fue la creación, en el año 1959, del Servicio Nacional de poliomielitis aguda.

Pero no fue hasta mediados de los años cincuenta cuando se aprobó la Ley de Accidentes del Trabajo de $1956^{12}$, que ya incluía una sección a la Rehabilitación (art. 140-143), estableciendo en su artículo 40 que "cuando las características de las lesiones lo aconsejen, los accidentados deberán ser sometidos a un tratamiento de rehabilitación que permita en cada caso, la recuperación más completa posible de su capacidad funcional y profesional para el trabajo".

Desde su creación, en 1948, la Organización Mundial de la Salud (OMS) también mostró un especial interés por el tema de la discapacidad, considerando la Rehabilitación como una de las principales herramientas para conseguir la recuperación integral del enfermo.

Es lógico pensar que esta nueva red asistencial y este conjunto de recursos materiales debía ir acompañado de un volumen adecuado de profesionales, formados tanto en la asistencia inmediata de urgencia como en el tratamiento de las secuelas derivadas de la enfermedad y en la reincorporación de la persona a la sociedad, tanto a nivel domiciliario como laboral. Por tanto, la demanda social, ante una necesidad más que evidente, es considerada clave para el nacimiento de un conjunto de profesionales con este tipo de competencias. Nos referimos al nacimiento de nuevas especialidades sanitarias como la Fisioterapia y Terapia Ocupacional, así como al desarrollo de nuevas especialidades médicas como la Rehabilitación que, a pesar de que fue definitivamente aprobada con posterioridad a las dos primeras ${ }^{13}$, estuvo influida por los mismos factores: el desarrollo económico y político del país, las epidemias de la poliomielitis ${ }^{14}$, y el establecimiento de un sistema de Seguridad Social mediante la Ley de Bases de la Seguridad Social de 1963 y su reforma de 1966 (Porras, 2006, p. 405). 
El caso de la Terapia Ocupacional, aunque no desarrollará el protagonismo de la Fisioterapia en este primer periodo, también adquirió un papel importante, especialmente en la fase de secuelas de la enfermedad, con el fin de obtener la independencia necesaria para el desempeño de las actividades esenciales de la vida diaria, la integración social de los niños mediante terapias recreativas o la posibilidad de adquirir un oficio para su inserción al mundo laboral. (Águila, Álvarez, Miangolarra y Rodríguez, 2002, p. 47). En 1964 se aprobó la Escuela de Formación en Terapia Ocupacional del Dispensario Central de Rehabilitación dependiente de la Dirección General de Sanidad ${ }^{15}$ que proporcionó la formación necesaria a estos técnicos, hasta la década de los noventa, fecha en la que se aprobó el título oficial de diplomado en Terapia Ocupacional. (Águila, 2000, p. 205)

Con las campañas de vacunaciones la poliomielitis dejó de ser una enfermedad amenazante para la vida del niño y, por tanto, el foco de atención fue dirigido ahora hacia el tratamiento del gran número de inválidos y de las secuelas derivadas en sus distintos grados, donde la Fisioterapia ocupaba el papel protagonista en la rutina diaria del enfermo. Fue en este momento, coincidiendo con el periodo final de la década de 1957, cuando las autoridades políticas y sanitarias, conscientes de esta necesidad y entendiendo que la figura profesional más preparada para esta tarea eran los ATS, decidieron crear una nueva especialidad, la de Fisioterapia. De este modo, el Real Decreto de 26 de julio de 1957 estableció la creación de esta nueva especialidad para los ATS ${ }^{16}$. Posteriormente, la Orden Ministerial del 7 de octubre aprobó el programa de estudios ${ }^{17}$ y de forma progresiva se fueron creando las primeras Escuelas para la enseñanza de esta especialidad.

A partir de este momento y de forma muy progresiva, las distintas unidades de Rehabilitación que se desarrollaron se caracterizaban por sus importantes carencias, tanto en recursos humanos como de espacios y materiales. Así queda reflejado en los diferentes informes redactados por los expertos consultores de la OMS que entre los años 1956 y 1975 visitaron nuestro país con el objetivo de evaluar la situación actual y los recursos destinados a la rehabilitación de personas con discapacidad, especialmente niños. Las visitas de expertos realizaron una evaluación de la red asistencial emplazada en las principales ciudades de nuestro país. En Madrid: el INRI, la Clínica del Trabajo, el Hospital del Rey, el Dispensario de la Cruz Roja y el Hospital San Rafael que eran de carácter privado, y el Hospital Niño Jesús. De todos ellos, a excepción del
Hospital Niño Jesús, creado para dar respuesta al problema de los niños con poliomielitis, todos contaban con experiencia en el ámbito de la reeducación en un periodo previo a la Guerra Civil. En Barcelona se crearon también distintas instalaciones, principalmente para ofrecer tratamiento a los afectados por la poliomielitis. Entre otros, cabe mencionar al Hospital de la Cruz Roja, el Hospital Clínico Universitario, el Hospital San Pablo, la Mutua Metalúrgica de Seguridad, el Hospital de enfermedades infecciosas, el Centro de Rehabilitación de Tarrasa y el Centro de Reeducación de los IMC de Montjuich. (Porras, Báguena y Toledo, 2017). Otros centros visitados fueron los principales hospitales de ciudades representativas como Valencia, Oviedo y Sevilla.

\section{POLIOMIELITIS Y LA FISIOTERAPIA}

La poliomielitis emergió como una enfermedad epidémica a finales del siglo XIX. Primero en Europa (1881) y, posteriormente, en la década siguiente, en EEUU y Canadá. La polio fue un problema de salud pública que para Europa finalizó con su erradicación en 2002. Smallman-Raynor y Cliff ${ }^{18}$ diferencian cuatro etapas de esta enfermedad, teniendo en cuenta aspectos epidemiológicos con fechas clave en la lucha contra la enfermedad: emergencia epidémica de la enfermedad (1880-1920), expansión global (19211955), retirada global (1955-1988) y erradicación global (1988-2002) (Ballester y Porras, 2012, p. 277). Siguiendo esta clasificación cronológica, el contexto de nuestro trabajo se centra en una fase de transición entre el final de la segunda y el inicio de la tercera etapa. En este periodo, la creciente cifra de afectados se prolongó en España hasta 1957, fecha que marcó un máximo histórico en el número de casos declarados. Fue en ese mismo año cuando se iniciaron los estudios de la especialidad de Fisioterapia para los ATS.

Los primeros brotes epidémicos en España datan de 1916, donde por primera vez las autoridades sanitarias adoptaron las primeras medidas sanitarias gubernamentales, entre las cuales destacó la obligatoriedad en la declaración de los casos de parálisis. Los siguientes brotes fueron en Madrid (1929), Santander (1930) y Mallorca (1932). A partir de los años 50 se produjo un aumento progresivo del número de casos repartidos por casi todo el territorio nacional (Toledo, 2010, p. 365).

En 1955 se iniciaron las primeras campañas de vacunación mediantevirus inactivados descubierta por Jonas Salk. Ésta inmunizaba contra los tres tipos diferentes de poliovirus y se aplicaba en forma inyectable 
en un conjunto de tres dosis. Dos años más tarde, la vacuna de Albert Sabin, con virus atenuados, hacía posible pensar en la erradicación debido a su fácil administración por vía oral y por permitir campañas masivas en breve tiempo a fin de crear inmunidad en toda la población (Rodríguez, 2012, p. 149).

En España, no se llevaron a cabo iniciativas oficiales hasta 1958, ya que el Estado consideraba que la inversión no era rentable en proporción al número de casos anuales, que se calculaba en unos dos mil. De 1958 a 1963, ante el innegable aumento de esas cifras, y coincidiendo con el interés en mejorar la imagen exterior del Régimen, se realizaron inmunizaciones con vacuna Salk (Ballester, 2008, p. 123) pero, aunque se les dio el nombre de "campañas" apenas contaron con publicidad y sólo podían acceder a ellas gratuitamente los acogidos a la beneficencia. Será a partir de 1963, cuando el Seguro Obligatorio de Enfermedad (SOE), dependiente del Ministerio de Trabajo y vinculado ideológicamente a Falange, inició la vacunación gratuita entre sus afiliados. Como respuesta, la Dirección General de Sanidad (DGS), perteneciente al Ministerio de la Gobernación y con clara influencia de militares católicos, continuó su vacunación con vacuna Salk pero ahora de forma gratuita (Rodríguez y Seco, 2009, p. 82).

La huella que la poliomielitis dejó en un número importante de niños de nuestro país, fue sin duda, una de las responsables del desarrollo de la Fisioterapia como especialidad, junto con otros factores como el gran número de heridos e inválidos con afectaciones motóricas,consecuencia del conflicto bélico de la Guerra Civil (1936-39) y las lesiones producidas por los accidentes laborales, fruto del desarrollo tecnológico, económico e industrial que provocaron un aumento en el número de discapacitados físicos (Toledo, 2013, p. 124).

Otro aspecto importante y decisivo en la puesta en marcha de la especialidad de Fisioterapia, fue el informe derivado de la primera visita realizada por los expertos de la OMS en 1956, llevada a cabo por Frank Safford y Kurt Jansson, donde ya recomendaron la creación en Madrid de una escuela de fisioterapeutas para formar profesionales que pudieran atender a la demanda social de inválidos derivados de las epidemias de poliomielitis. Otra medida urgente que apuntaban era la necesidad inminente de legislar el ejercicio de la Fisioterapia, de manera que se pudiera disponer del mayor número de profesionales formados en procedimientos específicos basados en la aplicación de medios físicos. El Gobierno ofreció la posibilidad de especialización a los ATS al considerarlos que disponían la formación sanitaria necesaria y que contaban con perfil profesional idóneo. Así, en 1957, se creó una nueva especialidad para los ATS adscrita a las Ilamadas escuelas de Fisioterapia, vinculadas a las Facultades de Medicina, las primeras de ellas en Madrid, Barcelona y Valencia (Toledo y Ballester, 2015).

El propio Real Decreto por el que se establece la especialización de Fisioterapia para los Ayudantes Técnicos Sanitarios, justificaba la necesidad de esta especialidad: "Una de las más necesarias es la de Fisioterapia, por el gran número de enfermos necesitados de recuperación y la escasez de personal dotado de los conocimientos necesarios teóricos y prácticos..., y por esa escasez de personal resulta conveniente admitir a la obtención del diploma a los actuales Practicantes y Enfermeras que acrediten la suficiente aptitud"19.

\section{INSTITUCIONALIZACIÓN DE LA FIGURA DEL FISIOTERAPEUTA EN ESPAÑA}

Aunque la Fisioterapia como profesión no aparece hasta el siglo XIX, es innegable que los medios físicos y su aplicación eran empleados por aquellos que se encargaban de atender y cuidar a las personas con enfermedades y lesiones (Gallego, 2007, p. 44). Ya desde la prehistoria tenemos constancia de la utilización de técnicas incipientes de la Fisioterapia como la aplicación de calor, masajes y baños con el fin de purificar el cuerpo impuro o liberarlo de los malos espíritus. Autores como Platón, Hipócrates y Galeno, también hacen alusión en sus obras a algunos tratamientos físicos para aliviar multitud de dolencias (Martínez y Chamorro, 2017, p. 6).

El nacimiento, desarrollo y consolidación de la Fisioterapia en España se produjo más tarde que en el resto de países europeos, condicionado por el contexto político, social y económico del país. Sin embargo, la evolución histórica de la Fisioterapia guarda aspectos comunes con el resto de Europa, por su vinculación a la Enfermería, primero en la figura del practicante y más tarde como especialidad de los ATS, hasta su posterior separación, consolidándose como disciplina y profesión independiente.

Se puede considerar que la figura del practicante es el precedente inmediato al fisioterapeuta. Previo a esta figura, se pueden encontrar los llamados curanderos, masajistas o sanadores, que utilizaban los medios físicos sin ningún tipo de formación previa. Posteriormente, serían los cirujanos menores o ministrantes los encargados de emplear los medios físicos (Chillón, 2008, p. 108). 
La figura del practicante no llegó a ser oficial como profesional titulado hasta 1857, quedando definida en la Ley de Instrucción Pública ${ }^{20}$, conocida como la Ley Moyano, siendo el sustituto del anterior cirujano menor o ministrante como refleja el artículo 40 de la presente ley: "Queda suprimida la enseñanza de la Cirugía menor o ministrante. El reglamento determinará los conocimientos prácticos que se han de exigir a los que aspiren al título de practicantes" (Siles, 2011, p.391).

Las modificaciones en el reglamento que regulaba tanto los estudios como las funciones del practicante fue una constante durante toda su existencia legal (1857-1953) debido, en parte, a la necesidad de convivir con otras profesiones auxiliares o subalternas de la medicina como la matrona y la enfermera (Herrera, Lasarte y Siles, 1996, pp. 259-268). El practicante era conocido como: [...] "el que practica. El que por tiempo determinado se instruye en la práctica de la medicina y la cirugía al lado y bajo la dirección de un facultativo. El que en los hospitales hace las curaciones o propina a los enfermos las medicinas ordenadas por el facultativo de visita. Encargados de ejecutar una clínica oficial o particular de las prescripciones que ordene el médico siendo responsable de su técnica pero no de su finalidad. Los practicantes son, en el arte de cuidar, lo que antes eran los cirujanos-ministrantes" (Siles, 1999, p. 242).

Algunos de estos profesionales practicantes se especializaron en la práctica del masaje y su formación estaba incluida en los programas de las escuelas de practicantes. Sus habilidades manuales y su labor sanitaria comenzaron a conocerse en diferentes ámbitos sociales, lo que provocó que esta figura fuera conocida con el nombre de practicantes-masajistas (Toledo, 2010, p. 364).

En 1953 se unificaron las enseñanzas de enfermeras, practicantes y matronas, creándose el nuevo título de Ayudante Técnico Sanitario (ATS) y se estableció la posibilidad de especialización, siendo la primera la de Matrona y posteriormente la de Fisioterapia ${ }^{21}$ dándoles la denominación de Ayudantes en Fisioterapia. Posteriormente, la Orden Ministerial del 7 de octubre ${ }^{22}$ aprobó el programa de estudios para la enseñanza de dicha especialidad. A partir de este momento se sucedieron diferentes Órdenes Ministeriales que regulaban la creación de distintas escuelas de Fisioterapia: Escuela de Fisioterapia en la Hermandad Salus Infirmorum de Madrid $^{23}$, la Escuela adscrita a la catedra de Patología Quirúrgica 1a de la Facultad de Medicina de la Universidad de Madrid en el Hospital Clínico San Carlos ${ }^{24}$, la Escuela de ATS masculinos del Hospital Infantil de San Rafael de Madrid ${ }^{25}$, la Escuela de ATS de la Sección Femenina de la Falange y de las J.O.N.S de Madrid ${ }^{26}$, las escuelas en distintas Facultades de Medicina como la de Zaragoza (1959), Valencia (1961), la Escuela de ATS de la Cruz Roja de Madrid (1962), la Escuela de ATS del Hospital de la Beata Maria Ana de Jesús de Madrid (1963) o la Escuela de ATS del Santiago Ramón y Cajal de Barcelona (1964) entre otras.

Los cambios producidos en la denominación del título de ATS de los años 70 y el paso de los estudios a la Universidad afectaron de la misma forma a la especialidad de Fisioterapia, separándose así de la disciplina enfermera. Tras repetidas solicitudes y conversaciones con la Administración, se creó una comisión interministerial entre expertos de educación y sanidad y los profesionales, a través de la Asociación Española de Fisioterapia, dando como resultado la promulgación del RD 2965/1980 de 12 de Diciembre, sobre la integración en la Universidad de los Estudios de Fisioterapia como escuelas universitarias de Fisioterapia ${ }^{27}$ (Meroño y Rebollo, 2013, p.260).

Desde el año 1983, la Fisioterapia quedó estructurada como carrera superior de primer ciclo en la Ley Orgánica de Reforma Universitaria ${ }^{28}$. Posteriormente, en 1986, se reconocía un Área de Conocimiento propia, denominada con el mismo nombre, reconociéndose así como ciencia autónoma. La Universidad de Valencia fue la primera que comenzó a impartir la enseñanza de Fisioterapia con rango universitario ${ }^{29}$ (Toledo, 2010, p. 369).

La última reforma educativa, enmarcada dentro del Espacio Europeo de Educación transformó los antiguos títulos de Diplomados en Grados, acorde al Real Decreto 1393/2007, de 29 de octubre, por el que se establece la ordenación de las enseñanzas universitarias oficiales ${ }^{30}$. Las escuelas de Diplomados en Fisioterapia, plenamente implicadas en este proceso, como muestra el Libro Blanco del Título de Grado en Fisioterapia, aprovechan esta oportunidad no sólo con el objetivo de contribuir a crear el Espacio Europeo de Educación Superior sino con la finalidad de reflexionar y revisar la práctica diaria para transformarla y adaptarla a un modelo ajustado a los contextos sociales y educativos actuales (Chamorro, 2016, p. 337)

\section{LA ESCUELA DE FISIOTERAPIA DE SALUS INFIRMORUM Y EL CENTRO “CASA DEL NIÑO” DE MADRID}

Consciente de las necesidades sanitarias y sociales que aquejaban a la ciudad de Madrid, provocadas por el brote epidémico de poliomielitis que tanto se cebó 
en la infancia española, María de Madariaga, presidenta de la Hermandad Salus Infirmorum ${ }^{31}$, consideró la necesidad de ofrecer un tratamiento específico a los niños que sufrían las secuelas motóricas provocadas por esta enfermedad. Su proyecto se centró en un centro al que llamó "Casa del Niño, Regina Angelorum". Previamente, María de Madariaga había visitado algunos centros europeos de Rehabilitación, incorporando los conocimientos adquiridos a la Casa del Niño, lo que posibilitó el desarrollo de un centro para la atención del niño inválido de cualquier afección.

Su ambicioso proyecto incluía además, una escuela de Fisioterapia, para proporcionar formación específica especializada a los ATS, convirtiendo a su vez el centro en un centro asistencial para llevar a cabo las enseñanzas teórico-prácticas de una Escuela de Fisioterapia.

El centro estaba situado en la calle de los Olivos número 2, en el barrio madrileño de Metropolitano. Fue inaugurado oficialmente el día 27 de junio de 1957 en un acto al que asistieron el alcalde de Madrid, Conde de Mayalde, el presidente de la Junta Provincial de Menores, el decano de la Facultad de Medicina y un importante número de prestigiosos médicos entre los que se encontraba Manuel Blanco Argüelles y el pediatra y fundador de la Sociedad de Pediatría de Madrid, Carlos Sainz de los Terreros, Joaquin Valenzuela, director de la Escuela de Visitadoras de la Cruz Roja, entre otros.
Las instalaciones fueron bendecidas por el obispo auxiliar de Madrid-Alcalá, D. José María García Lahiguera, acompañado por D. Ricardo Blanco, consiliario de Salus Infirmorum ${ }^{32}$ (Véase imágenes 1 y 2 ).

La Casa del Niño estaba compuesta por varios pabellones independientes donde se realizaban distintas actividades: la asistencia al niño prematuro; la atención a los niños afectados de trastornos motores, en el que se prestaban todos los servicios a través de un internado, dispuesto tanto para niños como para alumnas; y la atención a niños sanos, en la guardería infantil para la primera infancia. El centro conjugaba la atención asistencial con la docente ya que en ella se albergaba, además de la Escuela de Fisioterapia, la Escuela de Diplomadas de Niños, para la capacitación de personal con aptitudes para cuidar a niños sanos.

La Escuela de Fisioterapia, a través de la transmisión de conocimientos teóricos y prácticos, nace con el fin de atender y poder prestar ayuda eficaz a los niños con problemas motores que por nacimiento, enfermedades nerviosas, musculares, accidentes fortuitos, reumatismos, alteraciones en la forma y posición de los huesos, y otras muchas causas origina en ellos defectos en la marcha, deformaciones, atrofias y disminución de las funciones normales del tronco, brazos y piernas ${ }^{33}$. Así, las patologías más frecuentes eran las derivadas de la poliomielitis, parálisis cerebral infantil y espina bífida (Toledo, 2010, p. 416).

Imagen 1. La Casa del Niño

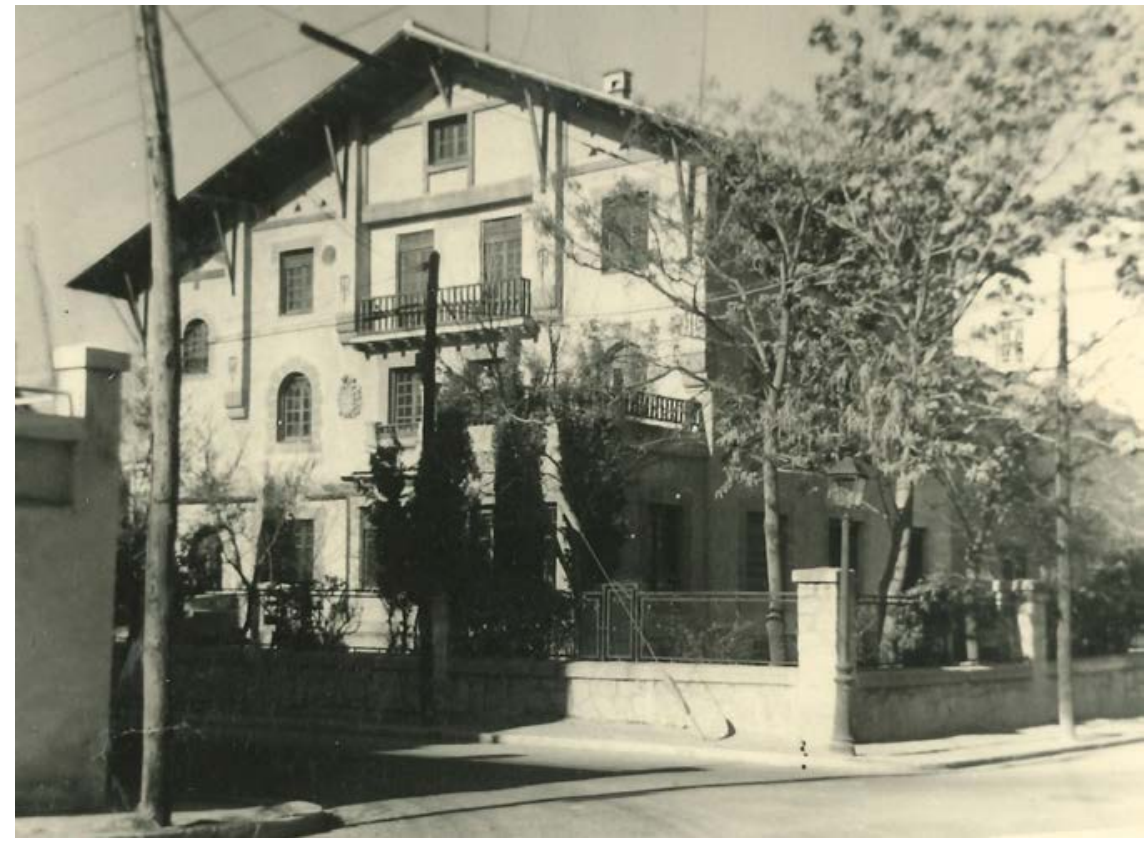

Fuente: Salus Infirmorum. 
Imagen 2. Inauguración del centro. María de Madariaga junto al Alcalde de Madrid y el Obispo auxiliar de Madrid

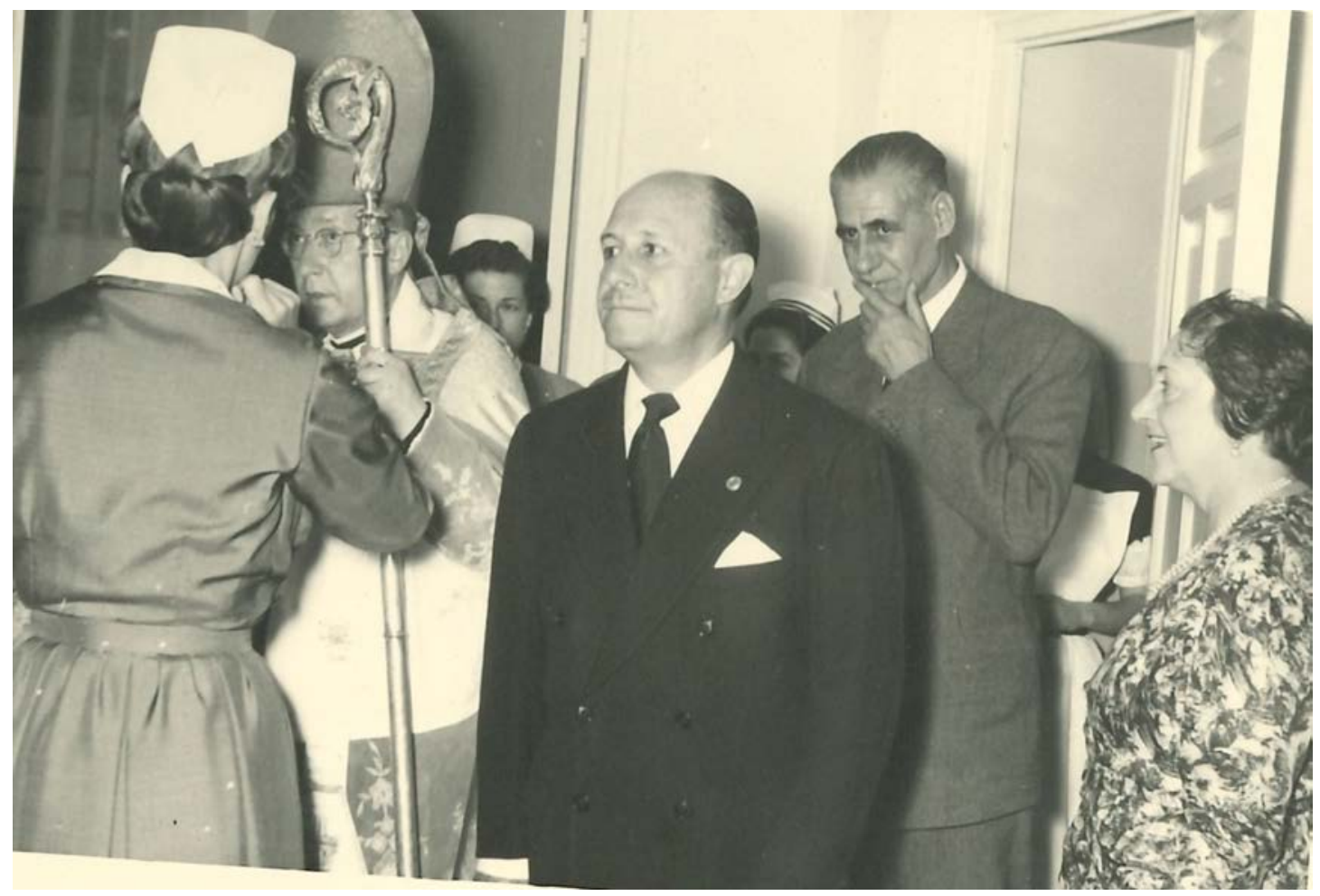

Fuente: Salus Infirmorum.

La creación de esta Escuela no solo dio respuesta a la atención a los enfermos necesitados de recuperación, sino que proporcionó la formación necesaria a las enfermeras, forjando un personal especializado con grandes conocimientos teórico-prácticos.

En 1956, Salus Infirmorum elevó al Ministerio de Educación Nacional, la propuesta de creación de la Especialidad de Fisioterapia, en el marco de la legislación vigente del momento. Al mismo tiempo, según consta en las fuentes consultadas del archivo de la asociación, se organizaban estos estudios de forma privada, con el apoyo y dirección del destacado Médico Rehabilitador Manuel Blanco Argüelles ${ }^{34}$ y del traumatólogo Dr. Iruegas, ese mismo curso académico 1956-1957, careciendo de validez oficial. (Chamorro, 2016, p.202)

Al año siguiente, el 26 de julio de 1957, el Ministerio de Educación Nacional, haciéndose eco de esta necesidad, promulgó el Decreto de creación de esta especialidad $^{35}$, autorizando Salus Infirmorum la creación de una Escuela para la enseñanza de Fisioterapia ${ }^{36}$. Además, la Comisaría de Asistencia Social del propio Ministerio, con fecha 6 de junio de 1958 reconocía Obra de Interés Social al centro de la Casa del Niño ${ }^{37}$.
Para cursar las enseñanzas de esta especialidad se requería estar en posesión del título de Ayudante Técnico Sanitario Femenino, tener menos de treinta y seis años cumplidos y no padecer defecto físico que imposibilitara el ejercicio de la profesión. Asimismo, podían aspirar al ingreso en esta Escuela las que, estando en posesión del título de Enfermera o Practicante, aprobaran un examen de ingreso sobre Física, Química, Fisiopatología de la respiración y de la circulación y nociones de patología del aparato locomotor.

La enseñanza constaba de dos cursos de ocho meses de duración cada uno, divididos en dos semestres (Ver tabla 1).

Los dos primeros meses del curso eran considerados un periodo de prueba para seleccionar a las alumnas, tanto desde el punto de vista físico, como intelectual y moral. Pasado ese periodo, las alumnas eran sometidas a distintas pruebas, entre ellas las físicas, para decidir sobre su aptitud hacia la profesión.

Al final de cada curso, las alumnas realizaban un examen teórico-práctico que si no era superado suponía la repetición del curso completo. En el caso de que 
Tabla 1. Programa de la Especialidad de Fisioterapia

\begin{tabular}{|c|c|c|}
\hline & PRIMER SEMESTRE & SEGUNDO SEMESTRE \\
\hline Primer Curso & $\begin{array}{l}\text { Anatomía } \\
\text { - } \quad \text { Fisiología } \\
\text { - Análisis del Movimiento } \\
\text { - Prácticas de gimnasia }\end{array}$ & $\begin{array}{ll}- & \text { Masaje } \\
- & \text { Mecanoterapia } \\
- & \text { Anatomía de la Piel } \\
- & \text { Electroterapia } \\
- & \text { Hidroterapia } \\
- & \text { Prácticas de gimnasia } \\
- & \text { Psicología } \\
- & \text { Deontología }\end{array}$ \\
\hline Segundo Curso & $\begin{array}{ll}\text { - } & \text { Rehabilitación en las afecciones } \\
& \text { quirúrgicas } \\
\text { - } & \text { Prácticas de Reeducación postraumática } \\
\text { - } & \text { Gimnasia correctiva } \\
\text { _ } & \text { Psicología }\end{array}$ & $\begin{array}{l}\text { - Rehabilitación en las afecciones } \\
\text { médicas } \\
\text { - } \quad \text { Prácticas de Reeducación reumática } \\
\text { - } \quad \text { Prácticas de Reeducación neurológica. } \\
\text { - Deontología. }\end{array}$ \\
\hline
\end{tabular}

Fuente: Salus Infirmorum.

no se aprobara en el segundo año, debían abandonar los estudios. Superadas favorablemente las pruebas finales, y mediante la presentación de la Tesis sobre un enfermo asistido por la alumna, la Escuela expediría el Diploma del Ministerio de Educación correspondiente a esta especialidad de cuerpo sanitario.

El primer curso de esta especialidad fue cursado por siete alumnas. Todas ellas finalizaron con éxito, la mayoría con sobresalientes y notables. Entre sus profesores se encontraba el Catedrático de Traumatología y Quirúrgica de la Facultad de Medicina, el Dr. Martín Lagos ${ }^{38}$ que, junto con el profesor Blanco Argüelles y el catedrático de Terapéutica Física, el profesor Gil y Gil, componían el tribunal evaluador (Véase imágenes 3 y 4).

Las primeras promociones de alumnas que finalizaron sus estudios de Fisioterapia fueron requeridas por la iniciativa privada y la administración para organizar, dirigir y llevar a cabo Centros y Servicios de Rehabilitación. Las primeras, salieron para Gorlitz (Vizcaya), a Málaga, para atender el Hospital Civil, el Marítimo de Torremolinos y el Sanatorio Parque San Antonio, a Córdoba, al Sanatorio del Santo Ángel de la Caja de Ahorros y Monte de Piedad. En Madrid, fueron solicitadas por la Clínica de Ciencias Neuroló- gicas, el Instituto de Seguridad e Higiene en el Trabajo y el Centro de Traumatología y Rehabilitación de la Ciudad Sanitaria de la Paz, donde fue trasladada la Escuela de Fisioterapia en octubre de 1965. Ma Jesús San Juan, la subdirectora de la Escuela, fue la encargada de poner en marcha el servicio de Fisioterapia de este hospital.

El precio para cursar esta especialización en el curso 1966-1967 era de 500 pesetas al formalizar la matrícula y 500 pesetas mensuales.

De los profesores implicados en la docencia, y especialmente relacionados con el tratamiento de la enfermedad, cabe destacar la presencia del profesor Blanco Argüelles, sobre el que recaía la mayor parte del peso de la docencia, junto con el cirujano ortopédico y traumatólogo D. José Martínez. En la parte práctica, eran tres fisioterapeutas las encargadas de impartir la formación.

La actividad docente teórica de la Escuela de Fisioterapia comenzaba por las tardes, quedando la mañana destinada a las prácticas de la especialidad, desde las ocho hasta las dos de la tarde. La asistencia a las clases prácticas se realizaba todos los días excepto uno, ya que se libraba por la obligatoriedad de realizar guardias en el servicio de hospitalizados. Este turno 
Imagen 3. Alumnas durante el desarrollo de una clase teórica

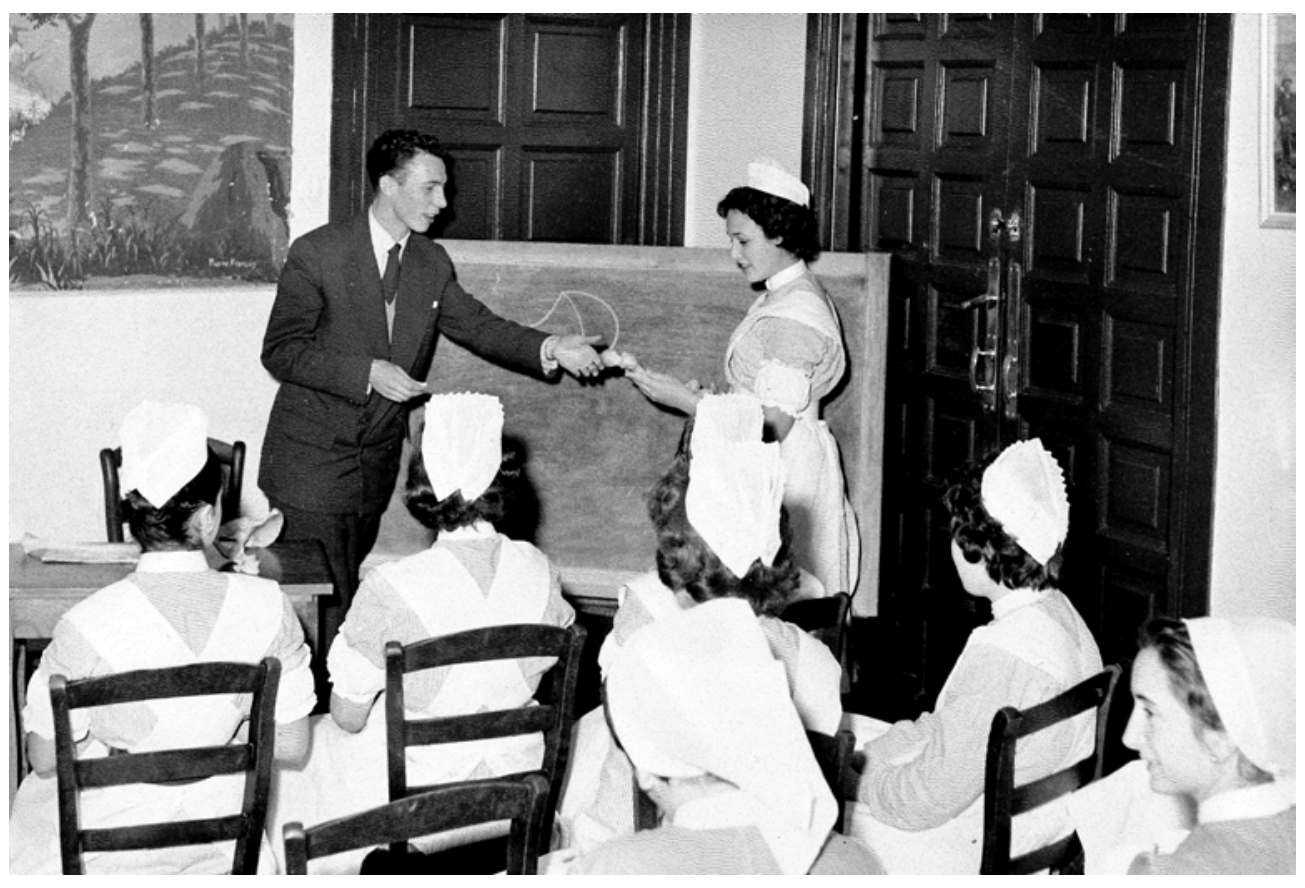

Fuente: Salus Infirmorum.

Imagen 4. Alumnas en clases prácticas

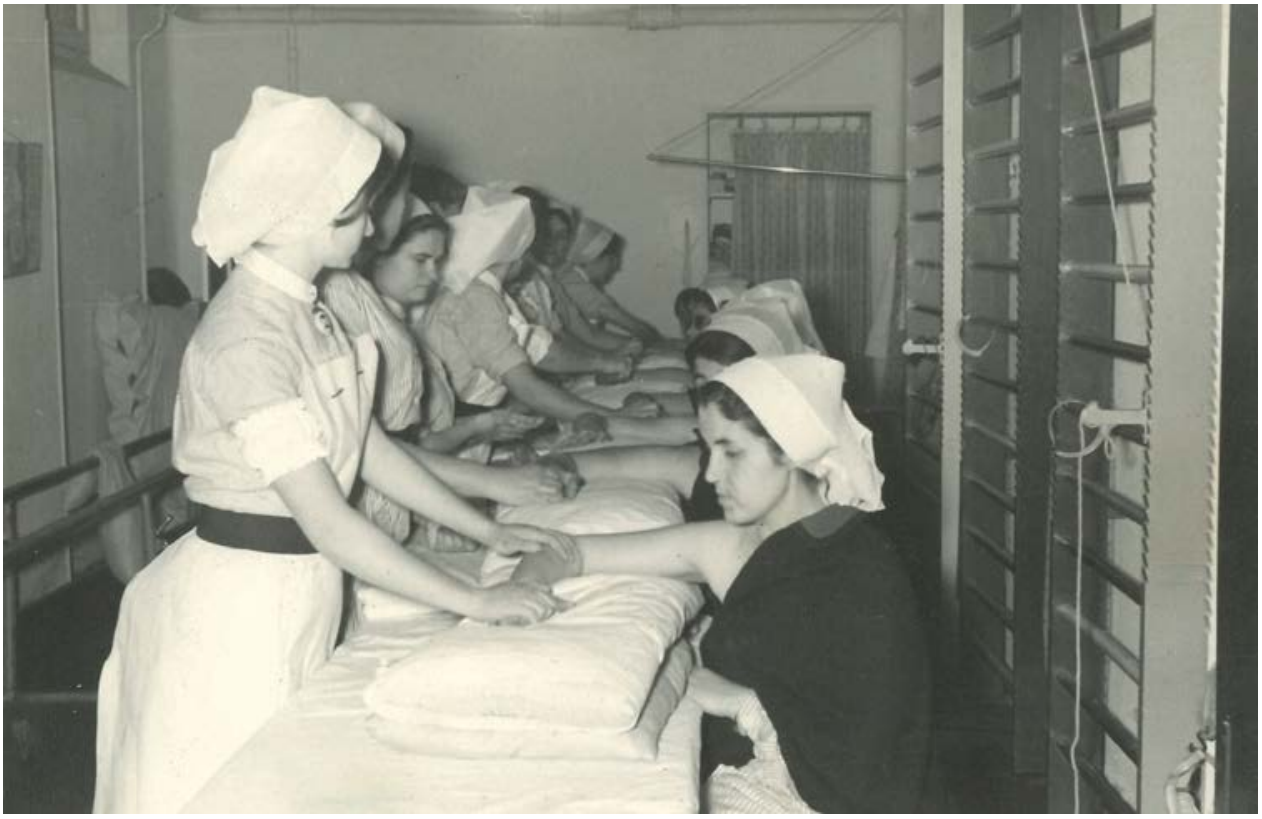

Fuente: Salus Infirmorum.

era realizado por un equipo formado por un fisioterapeuta y un estudiante de puericultura, con las funciones principales de mantener una vigilancia de los niños que permanecían en los lechos de escayola ${ }^{39}$.
La formación teórica y práctica se realizaba de forma simultánea y siempre en el propio centro. Otras escuelas, no realizaban la formación práctica hasta no haber finalizado la parte teórica, como ocurría en la 
Escuela Departamental de Valencia que desarrollaba la formación práctica en el Hospital Clínico de Valencia. Otras en cambio, impartían la teoría en las aulas de la Facultad de Medicina y las prácticas eran realizadas en los centros sanitarios, como en el caso de la Escuela de Fisioterapia de la Facultad de Medicina de Madrid que realizaban las prácticas en el Hospital San Carlos. (Toledo, 2013, pp. 128-138). Ninguna de las dos escuelas citadas, contaba con internado para alumnas.

La Casa del Niño atendía a niños en régimen interno, media pensión y ambulatorio, desde recién nacidos, sometidos a una estimulación precoz, hasta los 14 años. Para ello, contaba con los servicios que requería una rehabilitación de calidad para cualquier problema motor. Todo ello dirigido por una Junta de Equipo, presidida por María de Madariaga, la Directora General de la Institución, y en la que formaban parte el Director médico, el profesor D. Manuel Blanco Argüelles, la subdirectora, Da Ma Jesús San Juan, y contaban con otros profesionales como pediatra, psicólogo, asistenta médica-social, protésico, fisioterapeutas, ergoterapeuta, administradora y secretaria. El conjunto de profesionales implicados formaban un verdadero equipo multidisciplinar que trabajaba de forma coordinada en un centro caracterizado por un equipamiento similar al de otros centros de Rehabilitación (Águila, Álvarez, Miangolarra y Rodríguez, 2002, p.46).

Con estos datos, podemos afirmar que la escuela cumplía los requisitos para impartir las enseñanzas de
Fisioterapia con cierto nivel, descritos en el informe de los expertos de la OMS, en la que establecía que en cada una de las escuelas debía haber un director "consultivo", que debía ser un profesor de la facultad de medicina, que en el caso de Salus estaba vinculada la Universidad de Madrid, y en la figura del profesor Martín Lagos que participaba en la docencia de la escuela; un director "efectivo", médico especialista en Rehabilitación y un fisioterapeuta cualificado, dirección que recaía sobre el profesor Blanco Argüelles y la subdirectora Ma Jesús San Juan; y recomendaba, para aquellos discapacitados con mayores problemas de movilidad y que vivieran lejos de los centros, debería crearse un internado, que también lo contemplaba el centro. (Ballester, 2012, p.96).

En el centro se llevaban a cabo todos los tratamientos, adecuados al tipo de asistencia precisada, contando con los sistemas más modernos y avanzados de la época: piscina, para baños calientes y la realización de ejercicios bajo el agua, un gimnasio con mesas de trabajo para la movilización y el masaje, espalderas, planos inclinados, paralelas, escaleras con peldaños de diferentes alturas, poleas para ejercicios de brazos y piernas, patines, etc. Como servicios complementarios, contaban con ergoterapia, taller de ortopedia, psicología, logopedia, Rayos X y una sala para escayolas. También tenemos constancia de que contaban con un servicio de pulmón de acero $^{40}$ (Véase imágenes 5,6 y 7 ).

Imagen 5. Piscina del centro

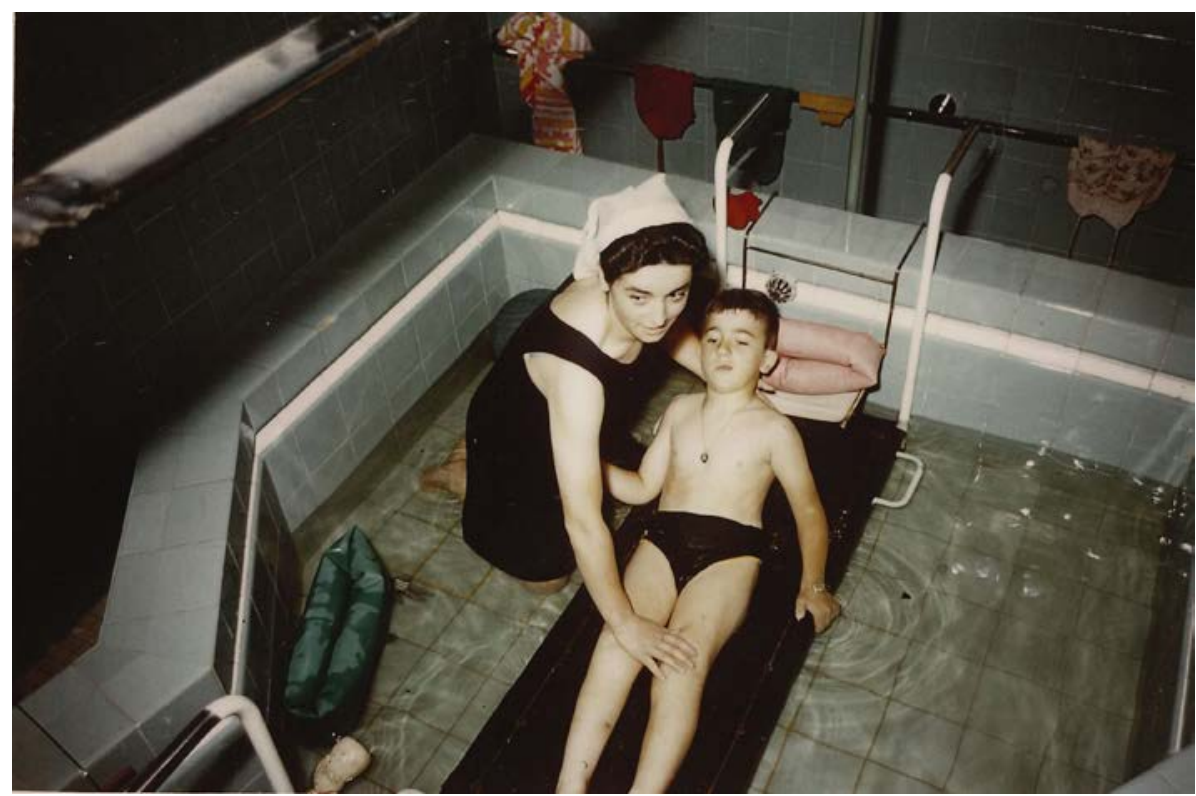

Fuente: Salus Infirmorum 
Imagen 6. Sala de Fisioterapia

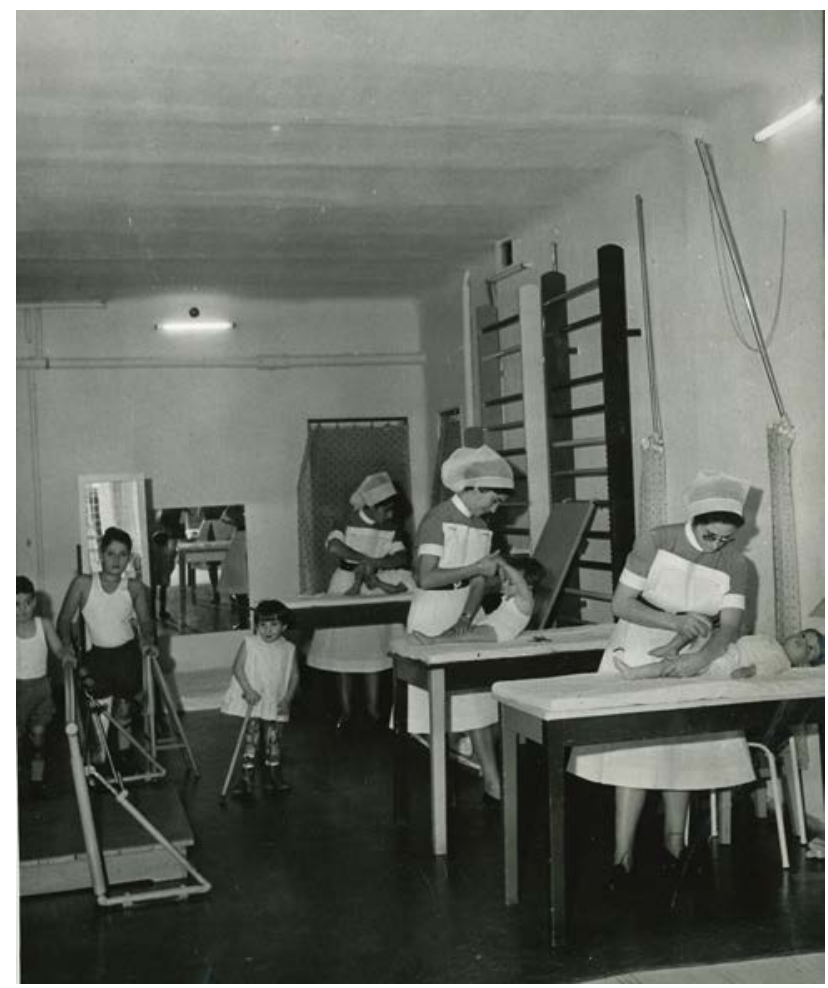

Fuente: Salus Infirmorum.

Imagen 7. Alumnas recibiendo una clase práctica

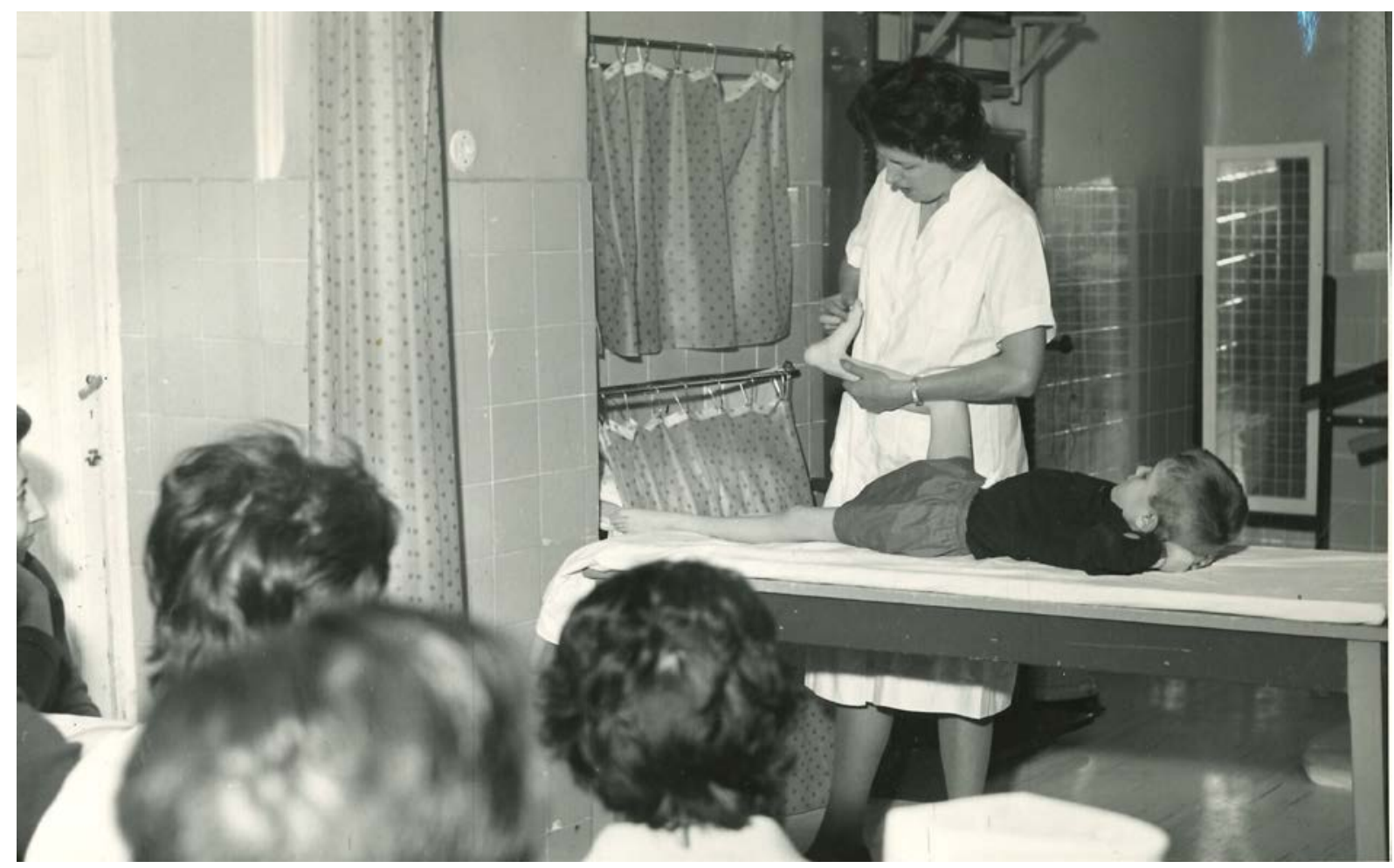

Fuente: Salus Infirmorum. 
Coordinado con el gimnasio, funcionaba el taller de prótesis, dirigido por Federico Bernardo de Quirós, donde se diseñaban y construían, bajo la dirección del profesor Blanco Argüelles, toda clase de equipos y ayudas técnicas: estribos, aparatos correctores para impedir la caída del pie, férulas de Saint-Germain, alimentador para el brazo, bicicleta, raquetas, portalápices, férulas de mano, taconeras, cubiertos, suspensiones, poleas y todo aquello, más o menos sofisticado, que contribuyera a dar más autonomía al inválido ${ }^{41}$ (Véase imágenes 8 y 9).

Imagen 8. Taller de prótesis

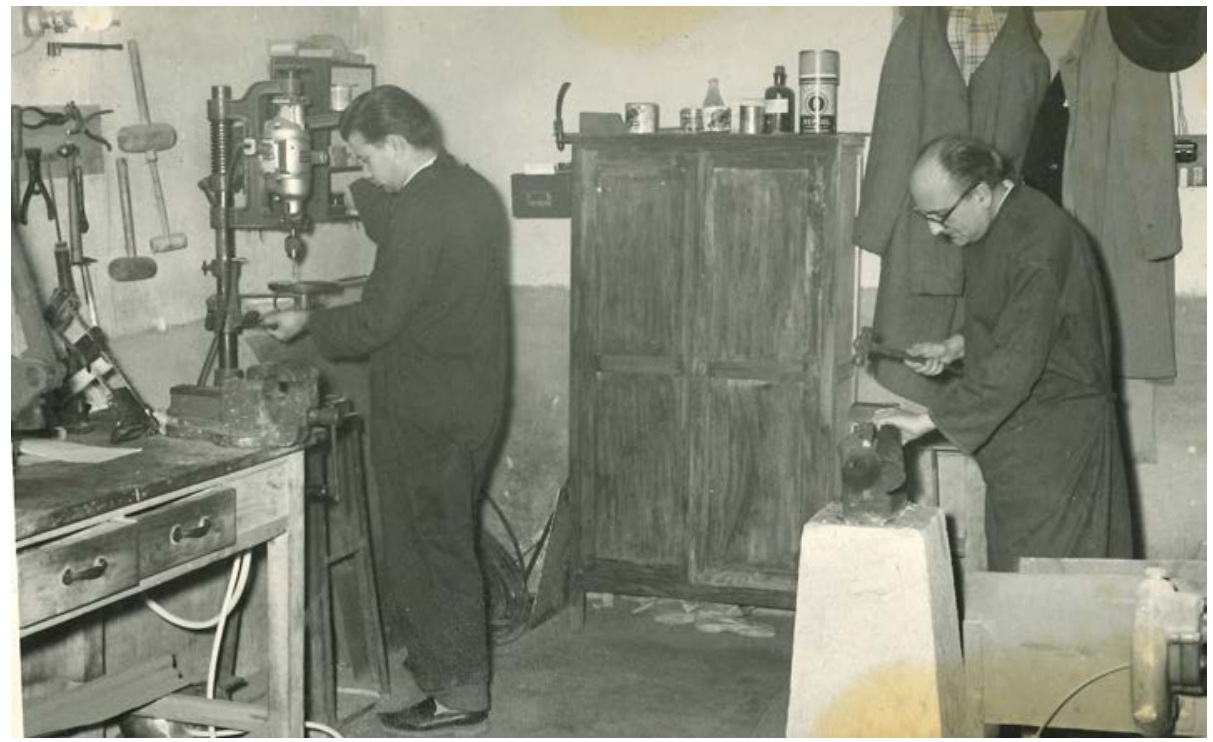

Fuente: Salus Infirmorum.

Imagen 9. Tratamientos realizados en el centro
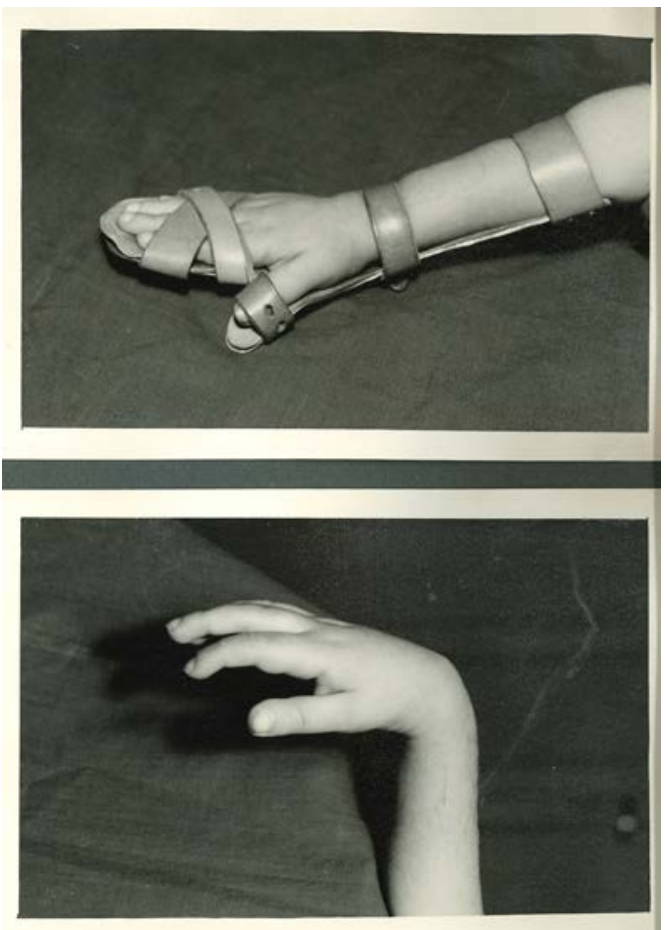

Fuente: Salus Infirmorum. 
En noviembre de 1962 se creó un departamento de Terapia Ocupacional para la readaptación funcional de todos los deficientes motores, cualquiera que fuera el origen de su parálisis ${ }^{42}$. Atendían tanto a niños como a adultos, aunque sólo los primeros podían hacerlo mediante internado o media pensión. Disponían de los medios más eficaces, valorados por la práctica y la expe- riencia de terapeutas tituladas. Dependiendo de la clase de parálisis, se realizaban ejercicios activos y de coordinación, y según la edad, para los más pequeños, juegos educativos; para los adolescentes, iniciación profesional; y para los adultos, toda clase de adaptaciones, dirigidas a la adquisición de la mayor independencia dentro de las actividades de la vida diaria (Véase imagen 10).

Imagen 10. Departamento de Terapia Ocupacional

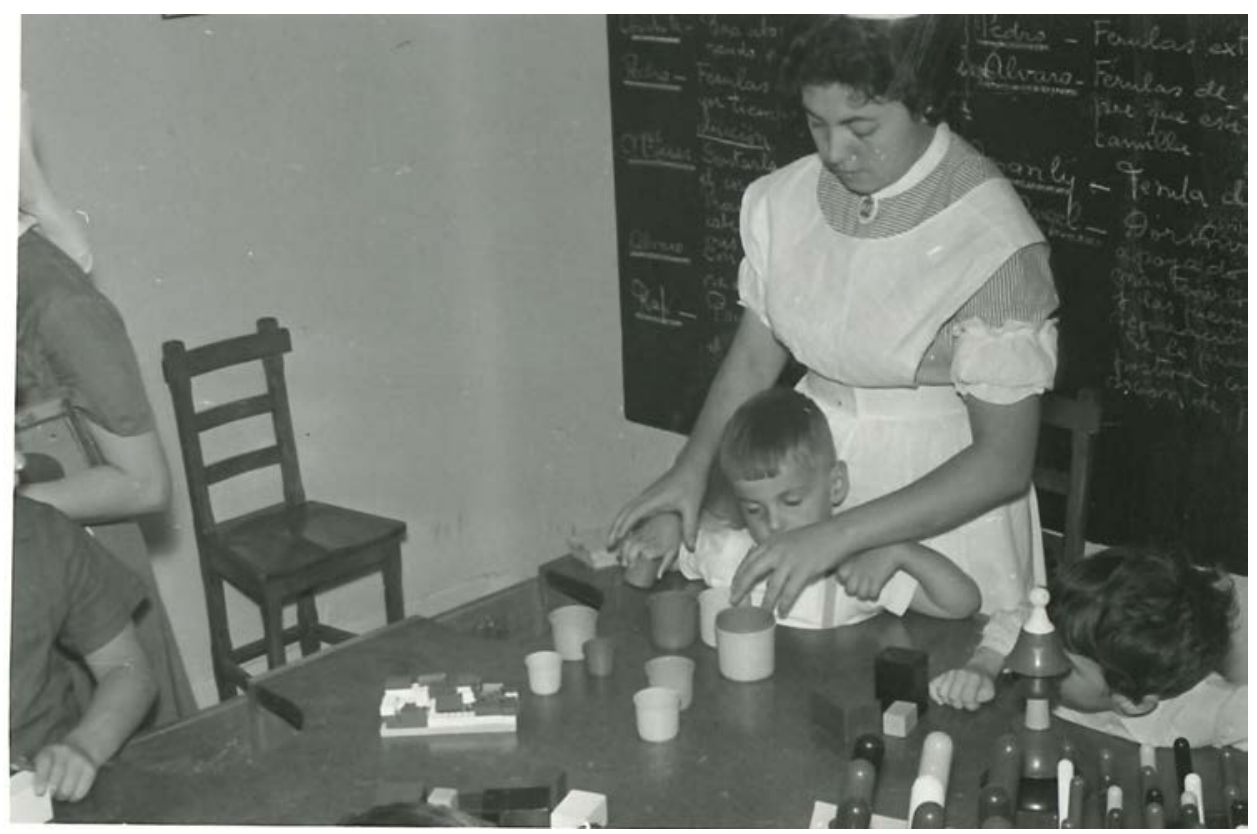

Fuente: Salus Infirmorum.

El internado tenía capacidad para treinta enfermos que se organizaban en dormitorios colectivos de tres, cuatro y cinco camas, fomentando el espíritu de compañerismo y la lucha contra la timidez y la tristeza, propias de estos niños incapacitados en mayor o menor grado.

Junto a los dormitorios había una sala de juegos, con una mesa especial para niños con espasticidad y una escuela de primaria que contaba con una maestra especializada en psicopedagogía infantil. Su función era la instrucción de los asistidos en régimen de internado, para que no se retrasasen en su formación cultural (Véase imágenes 11 y 12).

Para el tiempo de ocio, la Casa del Niño disponía de un amplio jardín enarenado, con aparatos y juegos mecánicos donde los niños, en la medida de lo posible, pasaban gran parte del día. También se les organizaban sesiones de cine, televisión, guiñol, teatro, visitas al circo, etc.
Además de las actividades propias del centro, se organizaban otro tipo de actividades externas, con diferentes características. Un ejemplo de ellas es la desarrollada en 1959, organizada desde la diócesis de Madrid y consistente en la peregrinación a Lourdes. Participaron cerca de 200 niños, de los cuales 20 eran internos de la Casa del Niño, quienes fueron acompañados por enfermeras del centro bajo la supervisión y liderazgo de María de Madariaga ${ }^{43}$.

Aparte del internado, el centro tenía capacidad para atender en régimen externo o mediopensionista a cuarenta niños para su rehabilitación.

Fuentes relacionadas con estadísticas de la actividad llevada a cabo en el centro, encontradas en el archivo de la Institución, muestran que se llevaban a cabo 80 tratamientos diarios de todo tipo, el $50 \%$ de los cuales era de los niños internos. Hasta 1967 se rehabilitaron un total de 683 niños, entre ellos: 363 tratados de secuelas poliomielíticas, 93 trau- 
Imagen 11. Comedor de la zona residencial del centro

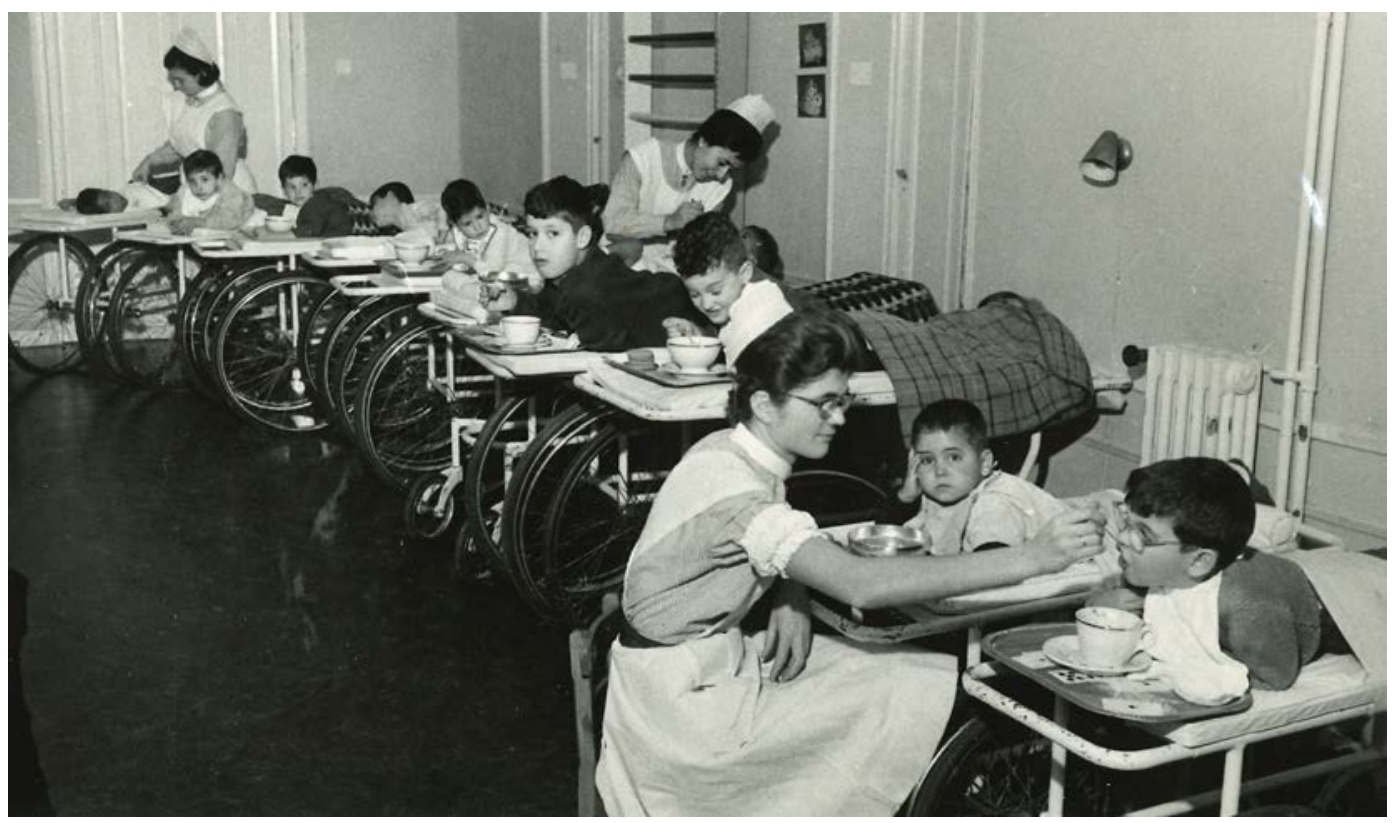

Fuente: Salus Infirmorum.

Imagen 12. Dormitorio de la residencia

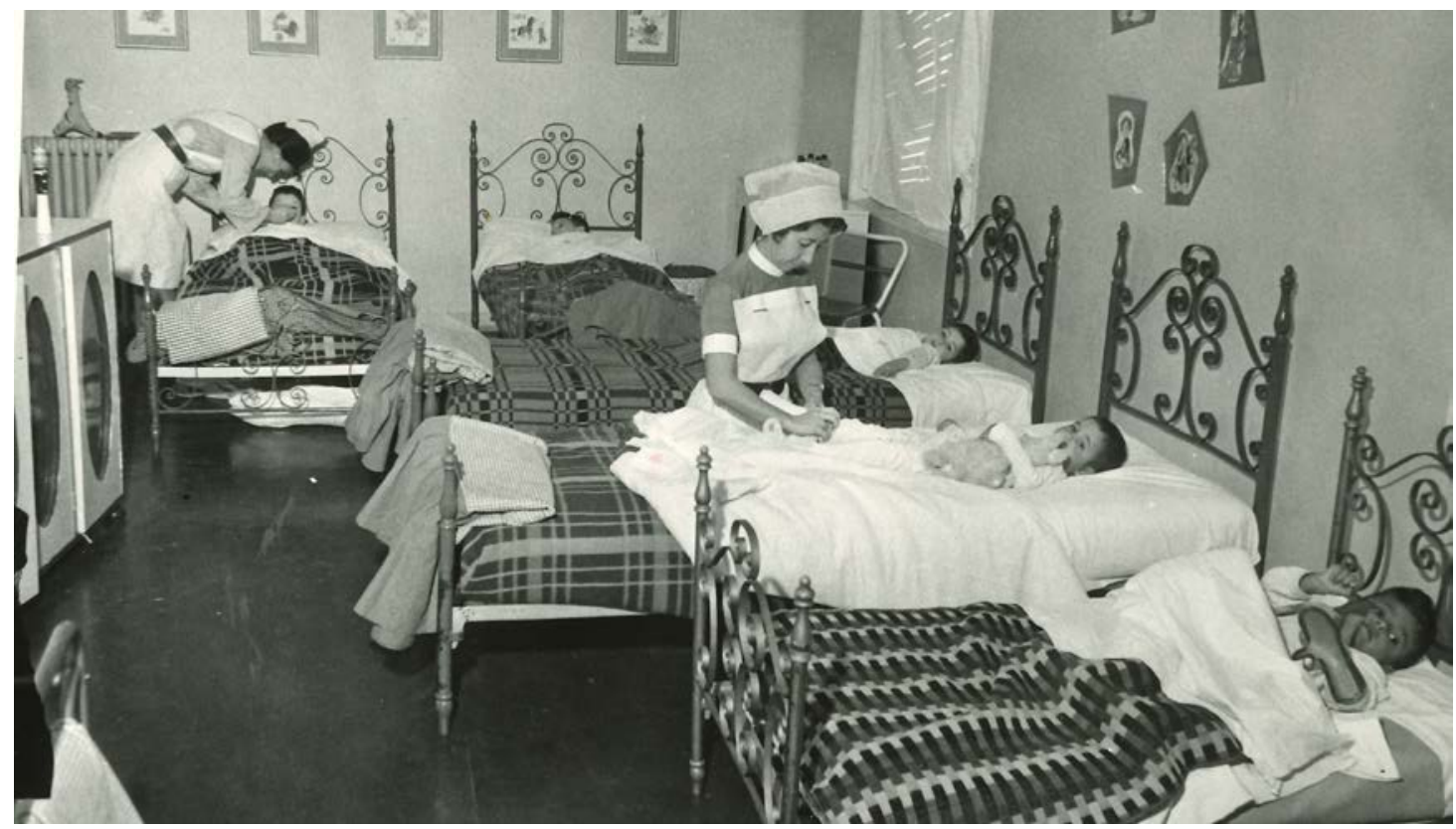

Fuente: Salus Infirmorum.

matizados, 22 con deformidades congénitas, 138 de parálisis cerebral, 22 de distrofia muscular y 40 de trastornos del lenguaje.

El 30\% de estos niños ingresaron en el centro a través de Cáritas Nacional y Diocesana, prestándo- les la Institución ayuda económica a todos ellos en un $50 \%$ de los gastos totales. El centro también les proporcionaba la recogida a en su domicilio a los mediopensionistas y ambulatorios, ya que disponía para ello de un microbús. Así mismo, ofrecía la posibili- 
dad de que los niños pudieran continuar sus estudios hasta el Bachillerato Elemental.

En 1963, Salus Infirmorum elaboró un documental que presentó a distintos congresos de Rehabilitación, en el que se muestra el funcionamiento del centro en sus distintos departamentos, principalmente en el de Rehabilitación y Fisioterapia (Chamorro y Pérez, 2009). La película fue realizada, según idea original de María de Madariaga, por Antonio J. Biosca, y describe el día a día de la Casa del Niño. La visión general del centro se inicia en el pabellón de puericultura y prematuros, y continúa con una muestra del funcionamiento del pabellón de Rehabilitación, donde pueden apreciarse la calidad y el valor de la asistencia a aquellos niños, junto con la enseñanza en la preparación de las profesionales Fisioterapeutas. A modo de ejemplo, la película analiza el caso de Antonio, un niño con gran afectación poliomielítica, desde la primera consulta para su valoración por el Dr. Blanco Argüelles, la aceptación por María de Madariaga a su ingreso como interno en el centro, la acogida por sus compañeros, pasando por su tratamiento en el gimnasio, su puesta en pie con las férulas de escayola y un entrenamiento para su autonomía en la vida diaria. Tras dos años desde el ingreso se le da de alta, consiguiendo que se valga por sí mismo a pesar de continuar con la parálisis de sus miembros inferiores: sube y baja escaleras, se tira y se levanta del suelo, cruza las calles en un tiempo mínimo, 10 metros en 12 segundos,... realizando cualquiera de las actividades de la vida ordinaria propias de su edad.

El centro contó con la visita de personajes ilustres, entre ellos su Alteza Real, el entonces Infante D. Juan Carlos de Borbón, en 1957, su Majestad la Reina Fabiola, reina de los belgas, el Cardenal Quiroga Palacios, Arzobispo de Santiago de Compostela y Presidente Nacional de Cáritas en 1962. En el plano más profesional, el centro fue visitado en junio de 1957, por Frank J. Safford ${ }^{44}$, uno de los consultores y expertos de la OMS, que elogió las instalaciones y dependencias; Jules Marie, directora de la escuela de enfermeras de Lovaina ${ }^{45}$; alumnos de la escuela portuguesa de enfermeras Artur Ravara del Hospital de los Capuchinos de Lisboa en $1958^{46}$; la distinguida enfermera y socióloga Miss Dixon en $1960^{47}$, y en la misma fecha, Birgit Brosgaard $^{48}$, Fisioterapeuta de Dinamarca, enviada también por la OMS. En 1963 la terapeuta ocupacional de la OMS Mercedes Abella ${ }^{49}$ (Véase imágenes 13 y 14).

En octubre de 1965, la escuela de Fisioterapia es trasladada al Centro de Traumatología y Rehabilitación de la Ciudad Sanitaria de la Paz, debido al incre- mento de actividad y al grado de madurez alcanzado, quedando definitivamente instalada con todo el equipo de médicos y enfermeras especialistas que dirigían la Casa del Niño y que se pusieron al frente de estos nuevos servicios organizados por la Seguridad Social del Estado.

La Escuela funcionó ininterrumpidamente hasta junio de 1983, fecha en que por imperativo de la Ley de Reforma Universitaria se clausuraron estas Escuelas. De sus aulas salieron un total de 373 fisioterapeutas en los 26 años de funcionamiento.

Salus Infirmorum, sin perder de vista las perspectivas de reanudar los estudios de Fisioterapia, y teniendo en cuenta las directrices que marcaba la Administración, inició esta segunda andadura en la formación en Fisioterapia en 1988, ajustándose a la nueva legislación. La Escuela de Fisioterapia se integró en la Universidad Pontificia de Salamanca, como previamente lo había hecho la Escuela de Enfermería, siendo su director el traumatólogo y profesor Pedro Guillén García, que entonces era el Director Médico del hospital de MAPFRE en Majadahonda.

No fue hasta 1992, cuando el Ministerio de Educación aprobó los estudios mediante el RD 473/1992, de 8 de mayo, por el que se reconocen efectos civiles a los estudios conducentes a la obtención del título de Diplomado en Fisioterapia, de la Escuela Universitaria de Fisioterapia de Majadahonda (Madrid), de la Universidad Pontificia de Salamanca ${ }^{50}$.

En la última reforma universitaria, enmarcada dentro del EEES, la escuela de diplomado en Fisioterapia se transformó en la Facultad de Enfermería y Fisioterapia Salus Infirmorum de la Universidad Pontificia de Salamanca.

\section{CONCLUSIONES}

La necesidad de atender a las personas con discapacidades físicas a causa del de los accidentes laborales y de tráfico, y por los brotes epidémicos de la poliomielitis, propició, en las décadas de los años 1950 y 1960, el desarrollo de la Fisioterapia, así como de otras profesiones sanitarias como las especialidades médicas de Rehabilitación, Medicina del Trabajo o la propia Traumatología y Ortopedia, así como la Terapia Ocupacional.

La Escuela de Fisioterapia de la Hermandad Salus Infirmorum fue la primera en ser aprobada a nivel ministerial, ofreciendo en un mismo centro, la Casa del Niño, una formación teórica y práctica integral e 
Imagen 13. Visita del Infante D. Juan de Borbón, en compañía de su hermana la infanta Dạ Margarita, alumna de puericultura de Salus Infirmorum

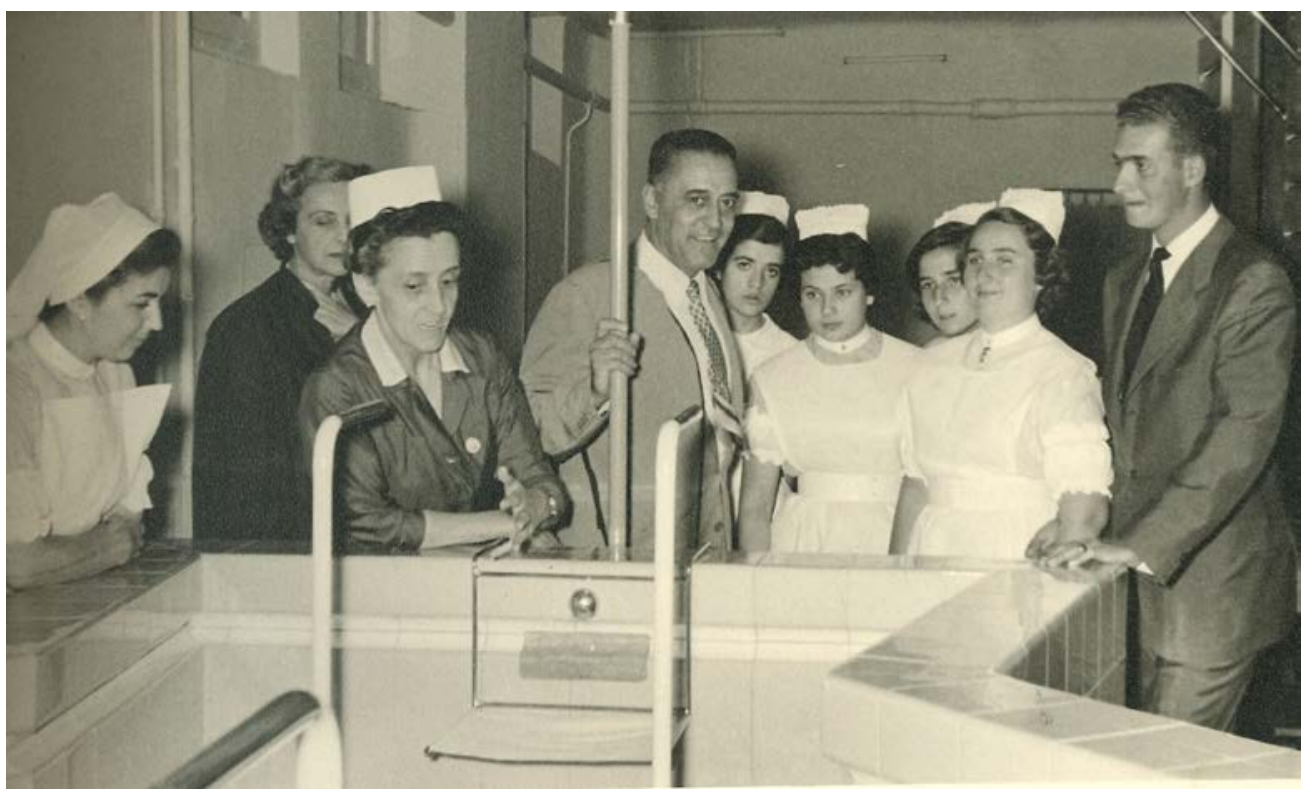

Fuente: Salus Infirmorum.

Imagen 14. Visita de la Reina Fabiola

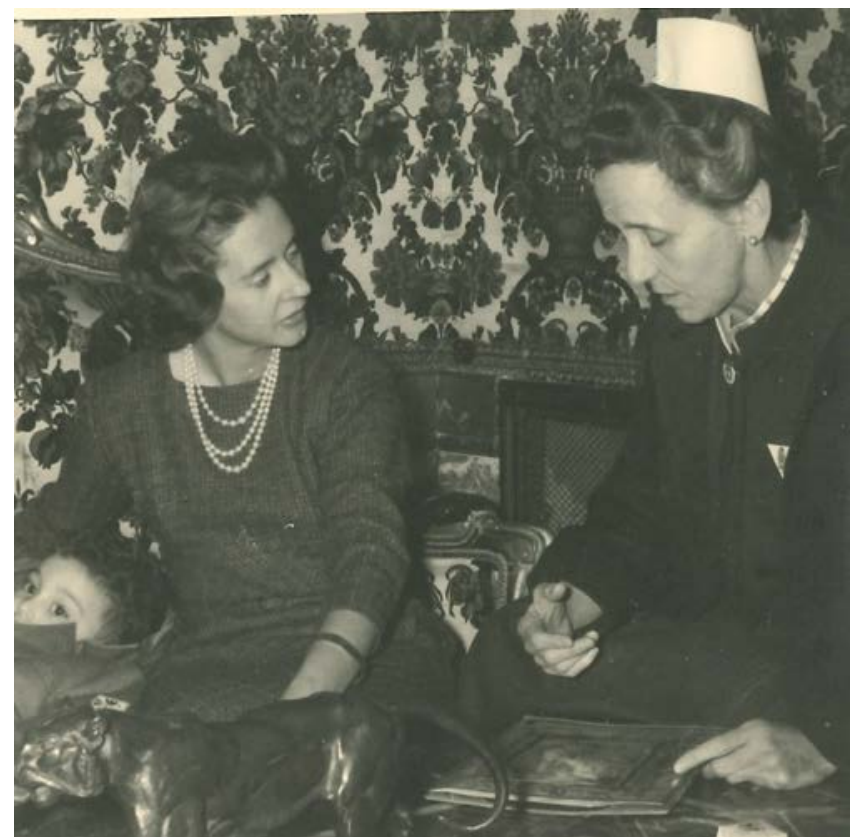

Fuente: Salus Infirmorum.

integrada. Este proyecto supuso un hito en la formación especializada de Enfermería y en el posterior desarrollo y reconocimiento de la Fisioterapia, detectando las principales áreas de estudio, a las que se asignaron como profesores a profesionales de reconocido prestigio.
María de Madariaga, fundadora de Salus logró que el centro infantil Casa del Niño fuera un centro pionero y un referente social, dando respuesta a las necesidades existentes del momento. Por un lado, a través de la atención y el cuidado a los niños con afectaciones motoras y por otro, ofreciendo una formación 
específica a las enfermeras, a través de la especialización en Fisioterapia.

En un entorno de escasez económica, y caracterizado por un marcado compromiso social, Salus Infirmorum contribuyó a la rehabilitación de muchos niños sin recursos económicos, que de otra forma se hubieran visto abocados al padecimiento de mayores e inhabilitantes secuelas físicas y psíquicas.

La escuela de Fisioterapia de Salus Infirmorum ha sabido adaptarse a las distintas reformas educativas hasta convertir sus estudios de Fisioterapia en título de Grado.

\section{NOTAS}

1. Decreto 26 de Julio de 1957 (BOE, 23-08-1957, no 215, p. 777).

2. Orden Ministerial del 7 de Octubre de 1957 (BOE 25-111957 , no 295, pp. 6894 a 6897).

3. La primera Orden de la que tenemos constancia corresponde al 28 de diciembre de 1957, por la que se crea una Escuela para la enseñanza de Fisioterapia en la Hermandad "Salus Infirmorum" de Madrid. Orden de 28 de diciembre de 1957(BOE 7-02- 1958, no 33, p. 1277).

4. (Safford, F. y Jansson, K., 1959) - Programa nacional de Rehabilitación de niños físicamente disminuidos. Informe sobre una misión en España. Madrid: Ministerio de la Gobernación. Dirección General de Sanidad, 96 páginas.

5. Decreto $1140 / 1969$, de 6 de junio sobre el reconocimiento de la Rehabilitación como especialidad médica. (BOE 1706-1969, no 144, p. 9464).

6. Orden de 28 de diciembre de 1957(BOE 7-02- 1958, no 33, p. 1277).

7. Ley de Accidentes de Trabajo (Gaceta de Madrid 31-011900, no 31, pp. 363-364).

8. El médico Antonio Oller Martínez (1987-1937) fue el responsable de la creación e instauración de la Medicina del Trabajo en España, y el director médico de la Clínica del Trabajo, creada en la reforma de la Ley de Accidentes del Trabajo de 1932 para garantizar la atención médica a los trabajadores accidentados (Bachiller, 1985, p. 41). Además esta ley estableció el seguro obligatorio de accidente del trabajo.

9. Ley reformada relativa a los Accidentes del trabajo. (Gaceta de Madrid 11/01/1922, núm. 11, de páginas 177 a 181).

10. Ley de accidentes de trabajo de 1932. (Gaceta de Madrid 07-07- 1932 no 189, páginas 179 a 180).

\section{AGRADECIMIENTOS}

Este estudio ha sido posible gracias a la generosidad de la Asociación Nuestra Señora Salus Infirmorum Diócesis de Madrid que nos ha permitido investigar en su archivo, analizando todos los documentos primarios allí dispuestos. El archivo está en proceso de catalogación y digitalización de sus fondos. Muchos de los documentos analizados se han podido contrastar con testimonios orales de personas coetáneas de la fundadora.

Agradecemos también a la Institución que haya cedido para este trabajo el material fotográfico que en él se expone.

11. Decreto de 6 de junio de 1949 por el que se establece la lucha sanitaria nacional contra la invalidez, (BOE 20-071946, n을 201, pp. 3227 a 3228)

12. Decreto de 22 de junio de 1956 por el que se aprueba el texto refundido de la Legislación de accidentes del Trabajo y Reglamento para su aplicación (BOE 15-07-1956, no 197, pp. 4614 a 4634).

13. El desarrollo de la Rehabilitación en España,no se logró totalmente hasta su reconocimiento como especialidad médica el 6 de junio de 1969 (BOE 19 de junio de 1969). El proceso de constitución de esta especialidad médica en España ha sido bien estudiado por J.M. Climent y A. Águila (Climent, 2001 y 2009; Águila, 2000).

14. Nuevamente, el tratamiento de la poliomielitis propulsó el desarrollo de una nueva especialidad médica, la Rehabilitación, donde se consolidaron tratamientos como los cuidados posturales, el fortalecimiento muscular, la mecanoterapia, la hidroterapia, las ortesis, y aparecieron otros nuevos, como los fomentos calientes de la Hermana Kenny. (Águila, 2000, p.116).

15. Decreto $3097 / 1964$, de 24 de septiembre, por el que se crea la Escuela de Terapia Ocupacional. (BOE 13-10-1964, no 246, pp. 13356 a 13356).

16. Decreto 26 de Julio de 1957 (BOE, 23-08-1957, no 215, p. 777).

17. Orden Ministerial del 7 de Octubre de 1957 (BOE 25-111957, no 295, pp. 6894 a 6897)

18. Smallman-Raynor, Matthew; Cliff, Andrew, eds. A world geography. Emergence to eradication. Oxford: Oxford University Press; 2006.

19. Decreto 26 de Julio de 1957 (BOE, 23-08-1957, no 215, p. 777). 
20. Ley de Instrucción Pública (Gaceta de Madrid 10-09-1857, no 1710, pp. 1-3).

21. Decreto 26 de Julio de 1957 (BOE, 23-08-1957, no 215, p. 777).

22. Orden Ministerial del 7 de Octubre de 1957 (BOE 25-111957, no 295, pp. 6894 a 6897).

23. Orden de 28 de diciembre de 1957(BOE 7-02-1958, no 33, p. 1277).

24. Orden 25 de febrero de 1958 (BOE 18-04-1958, no 93, p. 3379).

25. Orden de 3 de agosto de 1959 (BOE 21-10-1959), no 252, p.13433).

26. Orden de 3 de agosto de 1959 (BOE 21-10-1959), № 252, p.13433).

27. Real Decreto $2965 / 1980$, de 12 de diciembre, sobre integración en la Universidad de los estudios de Fisioterapia como Escuelas Universitarias de Fisioterapia. (BOE 19-011981, no 16,p. 1194).

28. Ley Orgánica 11/1983, de 25 de agosto, de Reforma Universitaria. (BOE 01-09-1983, no 209, pp. 24034 a 24042).

29. Real Decreto $2702 / 1983$, de 28 de septiembre, por el que se autoriza la transformación de la Escuela de Especialización de Fisioterapia de la Facultad de Medicina de la Universidad de Valencia en la Escuela Universitaria de Fisioterapia. (BOE 24-10-1983, № 254, p. 28773).

30. Real Decreto $1393 / 2007$, de 29 de octubre, por el que se establece la ordenación de las enseñanzas universitarias oficiales. (BOE 30-10-2007, no 260).

31. Salus Infirmorum fue creada en 1940 por María de Madariaga (1905-2001) como una Hermandad de enfermeras católicas cuyos fines fundacionales fueron preparar un futuro sanitario; actualizar, revalorizar y especializar, a aquellas que lo deseasen para una mejor capacitación; unificar, a todas las enfermeras en una Obra de la Iglesia y ayudar, a cada uno de sus miembros en todos los órdenes. Su labor se centró principalmente en la formación de Enfermeras, mediante la creación de distintas escuelas de Enfermería. La primera se crea en 1943 en Madrid, siendo su primer director el ilustre profesor D. Gregorio Marañón. Sus Escuelas se han ido adaptando a los cambios que el título de Enfermería ha experimentado a lo largo del tiempo, tanto en contenidos como en la propia definición de sus competencias. Desde 1941, Salus realizó una atención a los más desfavorecidos de los suburbios de la posguerra madrileña, a través del voluntariado de las enfermeras que integraban dicha institución, mediante improvisados centros asistenciales en las parroquias o en el propio domicilio si la situación del enfermo lo requería. (Chamorro, Siles, Díaz y Álvarez, 2016, p. 329).
32. ABC. 28 Jun 1957: 53.

33. Salus Infirmorum. Revista Firmes. 1957; 17: 31-35. La institución contaba con su propia publicación. La revista Firmes se publicó desde 1953 hasta 1965 y estaba dirigida a todos los profesionales sanitarios, especialmente a los que integraban la Hermandad.

34. Manuel Blanco Argüelles (1923-2017) fue el jefe del servicio de Rehabilitación de la Clínica del Trabajo de Madrid, y Presidente de la Sociedad Española de Rehabilitación y Medicina Física (SERMEF) durante el periodo 1972-1975.

35. Decreto 26 de Julio de 1957 (BOE, 23-08-1957, no 215, p. 777).

36. Orden de 28 de diciembre de 1957(BOE 7-02- 1958, no 33 , p. 1277).

37. DECRETO de 6 de junio de 1958 per el que se declaran de interés social las obras para la reforma y acoplamiento del edificio donde se instala la Escuela Oficial de Fisioterapia “Regina Angelorum”. (BOE 03-07-1958, no 158, p. 6223).

38. Salus Infirmorum. Revista Firmes, 1958, 21, p. 9.

39. Salus Infirmorum. Revista Firmes, 1957, 17, pp. 31-35.

40. Salus Infimorum (1960), Revista Firmes, 27, p. 26.

41. Salus Infirmorum. Revista Firmes, 1959, 22, pp. 18-19.

42. Salus Infirmorum. Revista Firmes, 1962, 21, p. 13.

43. $A B C 31$ de mayo de 1959.

44. Salus Infimorum (1957), Revista Firmes, 13, p. 25.

45. Salus Infimorum (1957), Revista Firmes, 13, p. 23.

46. Salus Infimorum (1958), Revista Firmes, 20, p. 25.

47. Salus Infimorum (1960), Revista Firmes, 27, pp. 4-6.

48. Briggit Brodsgaard fue enviada por la OMS entre 1960 y 1963 para describir el grado de formación de los fisioterapeutas en España. (Ballester, 2012, p. 97) Salus Infimorum (1962), Revista Firmes, 34, p. 23.

49. Mercedes Abella, terapeuta ocupacional enviada por la OMS, visitó España entre 1961 y 1963 y su estancia contribuyó de forma decisiva al desarrollo de la ergoterapia. En 1963, la revista de Salus Infirmorum FIRMES le realiza una entrevista. (Salus Infimorum, Revista Firmes, 1963, 39, p. 23).

50. Real Decreto 473/1992, de 8 de mayo, por el que se reconocen efectos civiles a los estudios conducentes a la obtención del título de Diplomado en Fisioterapia, de la Escuela Universitaria de Fisioterapia de Majadahonda (Madrid), de la Universidad Pontificia de Salamanca. (BOE 21-07-1992, no 174, p.24997). 


\section{BIBLIOGRAFÍA}

Águila Maturana, Ana María (2000), El debate medico en torno a la Rehabilitación en España (1949-1969) (tesis doctoral). Universidad Complutense, Madrid, España.

Águila Maturana, Ana María; Álvarez Badillo, Antonio; Miangolarra Page, Juan Carlos; Rodríguez Rodríguez, Luis Pablo (2002), "Influencia de las epidemias de la poliomielitis sobre la Rehabilitación en España (1949-1969)". Rehabilitación, Madrid, 36 (1), pp. 42-49.

Bachiller Baeza, Ángel (1985), La medicina social en España (El Instituto de Reeducación y la Clínica del trabajo 19221937), Valladolid, Universidad de Valladolid Servicio de Publicaciones.

Ballester, Rosa (2008), "La presentación internacional de las campañas de vacunación antipoliomielítica en España (1950-1963)". En: Perdiguero Gil, Enrique, et al., Las vacunas: historia y actualidad. Menorca, Institut Menorquí d’Estudis, pp. 123-138.

Ballester Añon, Rosa (2012), "Los organismos sanitarios españoles y la rehabilitación de los niños con discapacidades físicas: el caso español como modelo (1948-1975)", Revista Estudos do Século XX, 12, pp. 89-101.

Ballester Rosa, Porras, María Isabel, Báguena María José (2015), Políticas sanitarias locales puestas a prueba: consultores, expertos, misiones internacionales y poliomielitis en España, 1950-1975. História, Ciéncia, Saúde - Manguinhos, 22 (3), Río de Janeiro.

Ballester Añon, Rosa y Porras Gallo, María Isabel (2012), La lucha europea contra la presencia epidémica de la poliomielitis. Dynamis; 32 (2), pp. 273-285.

Bastos Ansart, Manuel (1921), Tratamiento de la parálisis infantil por el médico general. Saturnino Calleja, Madrid.

Chamorro Rebollo, Elena y Pérez Salido, Eustasio (2009), "Salus Infirmorum y la Casa del Niño". Curso La memoria paralizada: Identidades y vivencia de la poliomielitis y el síndrome postpolio, Universidad de Salamanca.

Chamorro Rebollo, Elena; Siles González, José; Díaz Pérez, Cristina; Álvarez López, Óscar (2016), "Nursing care in postwar Madrid", Investigación y Educación en Enfermería, 2016 34(2), pp. 329-341.

Chamorro Rebollo, Elena (2016), La influencia de María de Madariaga y de Salus Infirmorum en la Enfermería española en la última mitad del siglo XX (tesis doctoral). Universidad de Alicante, Alicante, España.

Chillón Martínez, Raquel (2008), La Fisioterapia en España 1957-2007. Estudio histórico, comparativo desde el enfoque ciencia, tecnología y sociedad (tesis doctoral). Universidad de Sevilla, Sevilla, España.
Climent Barberá, José María (2001), Historia de la Rehabilitación. De la medicina física a la atención de la discapacidad, EdikaMed, Barcelona.

Climent Barberá, José María (2009), Historia de la Rehabilitación. De la medicina física a la atención de la discapacidad, 2a ed., EdikaMed, Barcelona.

Gallego, Tomás (2007), Bases y fundamentos de la Fisioterapia, Madrid, Ed. Panamericana.

González Domínguez, José Ángel (2006), El proceso de institucionalización de la Fisioterapia en la Comunidad Valenciana y sus protagonistas (1950-2000) (tesis doctoral). Universidad Miguel Hernández de Elche, Alicante, España.

Herrera, Francisco; Lasarte, José; Siles, José (1996), “La organización colectiva y el ejercicio profesional de los Practicantes en el primer tercio del siglo XX". En: Hernández Martín, Francisca, (ed.), Historia de la Enfermería en España (desde la antigüedad a nuestros días), Madrid, Ed. Síntesis, p. 259-268.

Martínez Martín, María Luisa y Chamorro Rebollo, Elena (2017), Historia de la Enfermería. Evolución histórica del cuidado enfermero, Madrid, Elsevier.

Martínez Pérez, José (2009), “Consolidando el modelo médico de discapacidad: sobre la poliomielitis y la constitución de la traumatología y ortopedia como especialidad en España (1930-1950)", Asclepio, Revista de Historia de la Medicina y de la Ciencia 61(1), pp. 117-142.

Meroño Gallut, Javier y Rebollo Roldán, Jesús (2013), “Consolidación científica de la Fisioterapia en España. Un análisis a través de la historia". Cuestiones de Fisioterapia, 42 (E). Monografía. Historia de la evolución de la Fisioterapia (18132013), pp. 254-264.

Porras Gallo, María Isabel (2006), "La medicina y los seguros en el abordaje del problema de los inválidos del trabajo en España en la primera mitad del siglo XX". Historia, Ciências, Saúde-Manguinhos, 13(2) pp. 393-410.

Porras Gallo, María Isabel; Báguena Cervellera, María José; Toledo Maruhenda, José Vicente (2017), "Infraestructura y gestión del sistema hospitalario español en perspectiva de largo plazo". Congreso AEHE, Salamanca, España 6-9 Septiembre 2017.

Rodríguez Sánchez, Juan Antonio y Seco Calvo, Jesús (2009), "Las campañas de vacunación de la poliomielitis en España", Asclepio (51)1, p 81-116.

Rodríguez Sánchez, Juan Antonio (2012), "Poliomielitis y movimiento antivacunacionista en España (1955-1963)", । Congresso de História Contemporanea; Lisboa, Portugal, p. 145-159.

Siles, José (1999), Historia de la Enfermería, Alicante, Ed. Aguaclara. 
Siles González, José (2011), Historia de la Enfermería, Madrid, Difusión Avances en Enfermería.

Smallman-Raynor, Matthew y Cliff, Andrew (2006), A world geography. Emergence to eradication, Oxford, Oxford University.

Safford, Frank y Jansson, Kurt (1959), "Programa nacional de Rehabilitación de niños físicamente disminuidos". Informe sobre una misión en España. Madrid: Ministerio de la Gobernación. Dirección General de Sanidad.

Toledo Maruhenda, José Vicente (2010), La poliomielitis en España (1880-1970) y su impacto sobre el desarrollo de las técnicas en Fisioterapia (tesis doctoral), Universidad Miguel Hernández de Elche, Alicante, España.
Toledo Maruhenda, José Vicente (2013), “Terapias físicas frente al a enfermedad y sus secuelas en Madrid, Valencia y Castilla La Mancha. La institucionalización de la Fisioterapia en España". En: Porras Gallo, María Isabel, Ayarzagüena Sanz, Mariano, De las Heras Salord, Jaime y Báguena Cervellera, María José (coords.), El drama de la polio. Un problema social y familiar en la España franquista. Madrid, Ed de La Catarata pp.120-140.

Toledo Maruhenda, José Vicente y Ballester Añon, Rosa (2015), "Los intentos de rehabilitación del régimen franquista y los consejos de expertos internacionales para la rehabilitación y tratamiento fisioterápico de niños con discapacidades físicas (1960-1975)". En Perdiguero Gil, Enrique (ed.), Política, salud y enfermedad en España: entre el desarrollismo y la transición democrática. Universidad Miguel Hernández de Elche, Alicante. 